\title{
GTPase Regulators and Photoresponses in Cones of the Eastern Chipmunk
}

\author{
Xue Zhang, ${ }^{1}$ Theodore G. Wensel, ${ }^{1}$ and Timothy W. Kraft ${ }^{2}$ \\ ${ }^{1}$ Department of Biochemistry and Molecular Biology, Baylor College of Medicine, Houston, Texas 77030, and 2Department of Physiological Optics, School of \\ Optometry, University of Alabama, Birmingham, Alabama 35294
}

Vertebrate cone and rod photoreceptor cells use similar mechanisms to transduce light signals into electrical signals, but their responses to light differ in sensitivity and kinetics. To assess the role of G-protein GTP hydrolysis kinetics in mammalian cone photoresponses, we have characterized photoresponses and GTPase regulatory components of cones and rods from the cone-dominant retina of the eastern chipmunk. Sensitivity, based on the stimulus strength required for a half-maximum response, of the M-cone population was 38-fold lower than that of the rods. The relatively lower cone sensitivity could be attributed in part to lower amplification in the rising phase and in part to faster recovery kinetics. At a molecular level, cloning of chipmunk cDNA and expression of recombinant proteins provided standards for quantitative immunoblot analysis of proteins involved in GTPase acceleration. The ratio of the cGMP-phosphodiesterase inhibitory subunit $\gamma$ to cone pigment, 1:68, was similar to the levels observed for ratios to rhodopsin in bovine retina, 1:76, or mouse retina, 1:65. In contrast, the ratio to pigment of the GTPase-accelerating protein RGS9-1 was 1:62, more than 10 times higher than ratios observed in rod-dominant retinas. Immunoprecipitation experiments revealed that, in contrast to rods, RGS9-1 in chipmunk retina is associated with both the short and long isoforms of its partner subunit $\mathrm{G}_{\beta 5}$. The much higher levels of the GTPase-accelerating protein complex in cones, compared with rods, suggest a role for GTPase acceleration in obtaining rapid photoresponse kinetics.

Key words: photoreceptors; cones; rods; G-proteins; phosphodiesterase; RGS proteins; PDE $\gamma$; vision; retina

\section{Introduction}

Humans and other diurnal animals rely primarily on their cone photoreceptors for functional vision. Daylight vision, color discrimination, rapid motion detection, and finely focused images all rely on cones (for review, see Masland, 2001). Humans lacking rod function but retaining cone function have the relatively mild condition of night blindness. In contrast, those retaining rod function but lacking cone responses have very severe visual defects, (for review, see Birch, 1999; Hicks and Sahel, 1999). Therefore, it is of great interest to understand the biochemical properties of cones and the relationships between their molecular and physiological properties. Cone photoresponses have been recorded from some mammalian species (Kraft, 1988; Schnapf et al., 1990; Kraft et al., 1998; Schneeweis and Schnapf, 1999), but biochemical data are, for the most part, lacking, because no procedures have been developed for isolation of cone outer segments in amounts comparable with those obtainable from rod outer segments. Consequently we have a wealth of biochemical information about rods but only rudimentary information on the biochemistry of mammalian cones. In rod cells, quantification of the amounts of phototransduction components and characterization of their biochemical properties allow detailed modeling of the molecular mechanisms of phototransduction (Detwiler et al., 2000; Hamer, 2000; Leskov et al., 2000; Arshavsky et al., 2002). In

Received Aug. 21, 2002; revised Nov. 15, 2002; accepted Dec. 2, 2002.

This work was supported by National Eye Institute Grants EY11900, EY07981, and EY10573 and by the Welch Foundation. We thank Derron Allen and Jerry Millican for technical assistance and Trevor Lamb for helpful discussions on fitting the phototransduction gain.

Correspondence should be addressed to Theodore G. Wensel, Department of Biochemistry and Molecular Biology, Baylor College of Medicine, One Baylor Plaza, Houston, TX 77030. E-mail: twensel@bcm.tmc.edu. Copyright $\odot 2003$ Society for Neuroscience $\quad 0270-6474 / 03 / 231287-11 \$ 15.00 / 0$ cones, similar biochemical components are present, but their concentrations are mostly unknown.

Retinas of cone-dominant animals represent useful starting material for biochemical analysis of cone phototransduction as well as for electrophysiological recording. Two readily available examples are ground squirrels (Kraft, 1988) and chipmunks. We have analyzed photoresponses of the eastern chipmunk Tamias striatus and measured amounts of proteins essential for their inactivation phases. Because these proteins are found almost exclusively in photoreceptor outer segments, and because rods make a negligible contribution to their amounts, this quantification can be performed on crude extracts of total retina without purification of cone outer segments. Because the detection method relies on recognition by antibodies raised against orthologous proteins from other species, it was necessary to clone cDNA encoding the chipmunk proteins and to express them for accurate calibration of antibody sensitivity.

Our focus has been on proteins that determine the lifetime of transducin activation through regulation of the kinetics of G-protein GTP hydrolysis. The reason is that major differences between cones and rods include much lower sensitivity and faster recovery kinetics in cones. Faster recovery may contribute to lowering sensitivity. In both cones and rods, recovery is the slow phase of photoresponses, and it has been proposed that the ratelimiting step in rod transduction is transducin GTP hydrolysis (Sagoo and Lagnado, 1997; Nikonov et al., 1998). Immunostaining in bovine and human retina (Cowan et al., 1998; Zhang et al., 1999) suggested that cones had higher RGS9-1 content than rods but did not allow quantitative estimation of relative amounts.

We report here results from electrophysiological recordings of light responses in chipmunk rods and cones, along with quanti- 
fication of the GTPase accelerating proteins RGS9-1, $\mathrm{G}_{\beta 5}$, and cGMP phosphodiesterase inhibitory subunit $\gamma(\operatorname{PDE} \gamma)$ in chipmunk retina.

\section{Materials and Methods}

Buffers. Standard buffers were buffer A (in mM: 10 3-(N-morpholino) propane sulfonic acid (MOPS), $\mathrm{pH} 7.0,30 \mathrm{NaCl}, 60 \mathrm{KCl}, 2 \mathrm{MgCl}_{2}$, and 1 DTT and $\sim 20 \mathrm{mg} / \mathrm{l}$ phenylmethylsulfonyl fluoride), buffer B (in mм: 25 Tris and 192 glycine, $\mathrm{pH} 8.3$ ), buffer $\mathrm{C}$ (in mM: $10 \mathrm{MOPS}, 1 \mathrm{MgCl}_{2}, 50$ $\mathrm{NaCl}$, and 0.1 EDTA, pH 8.0), and buffer D (in mM: 10 HEPES, $100 \mathrm{NaCl}$, and $2 \mathrm{MgCl}_{2}$ ). Other buffer components and conditions were varied as indicated throughout.

Animal and tissue preparation. The eastern chipmunk is common in rural and suburban neighborhoods of the southeastern United States. Animals were trapped by permit in Jefferson County Alabama. Animals were housed singly with a hiding tube and ad libitum access to food and water; captivity was well tolerated, because some animals were kept for $>4$ years. All experimental protocols were approved by the University of Alabama Institutional Animal Care and Use Committee. To start, a chipmunk was dark-adapted overnight and then killed by carbon dioxide asphyxiation. Details of the tissue preparations and electrolytes have been given previously (Kraft et al., 1993). Briefly, the retina was isolated under infrared light in Lebovitz's L-15 medium and stored at $4^{\circ} \mathrm{C}$ in the dark. Experiments were performed on the same retina for $2-3 \mathrm{~d}$; each tissue sample lasted 3-4 hr. For each experiment, one-third of a retina $(\sim 3 \times 4 \mathrm{~mm})$ was removed from cold storage and chopped under infrared light to produce small pieces of retina $\sim 50-100 \mu \mathrm{m}$ on a side and then warmed to near body temperature in a perfusion chamber. The circulating dark current of individual rods or cones was recorded by drawing the outer segment into a suction electrode, whose inner diameter matched the outer segment diameter of the cell. The photocurrent and stimulus monitor signals were digitized with hardware (MIO16) and software (LabView) from National Instruments (Austin, TX). A stimulus set consisted of 5-30 responses to the same wavelength and intensity of light. The light bench focused a $440-\mu \mathrm{m}$-diameter spot of light at the plane of the cells. The wavelength was controlled with three-cavity interference filters (Andover Corp., Salem, NH) with an average bandwidth of $10 \mathrm{~nm}$. Neutral density filters (Reynard Corp., San Clemente, CA) attenuated the light. Calibration of unattenuated light at each wavelength was performed daily with a photometer (model 350; Graseby Optronics, Orlando, FL).

Measuring the action spectra. Spectral sensitivity of the visual pigments was estimated by measuring the action spectra using the criterion response method and the photocurrent responses of individual cones. The action spectrum was determined for up to 20 wavelengths at $\sim 20 \mathrm{~nm}$ intervals between 380 and $760 \mathrm{~nm}$. Spectral sensitivity was measured by adjusting the intensity of light at each wavelength to produce a criterion response of $\sim 25 \%$ of the maximum current. The sensitivity at each wavelength was measured relative to a standard wavelength, $(500 \mathrm{~nm})$. Initially, for each cell, the complete intensity response function was determined at $500 \mathrm{~nm}$. Subsequently, for each test wavelength, two or three light intensities were used to obtain current responses of $10-60 \%$ of maximum. Sensitivity measures at the standard wavelength were repeated after every two or three test wavelengths to avoid errors attributable to changes in the physiologic state of the cell or electrode seal.

Calculations of phototransduction gain. The gain factor for the rising phase of the photoreceptor response was estimated by fitting Equation 22 from Pugh and Lamb (1993), given below as Equation 1, to the initial portion of the rising phase of the photocurrent response. The fitting was performed simultaneously to responses to two to five intensities in the linear range (see Fig. 2C,D).

$$
r(t)=R_{\max }\left\{1-\exp \left(-1 /{ }_{2} A \Phi\left(t-t_{\mathrm{d}}\right)^{2}\right)\right\} \quad \text { for } t>t_{\mathrm{d}},
$$

where $R_{\max }$ is the maximum response; $t_{\mathrm{d}}$ is a combined delay factor for all the biochemical reactions, and $A$ is the gain factor for the activation phase of phototransduction (Lamb and Pugh, 1992; Pugh and Lamb, 1993). The number of photoisomerizations, $\Phi$, is the product of the stimulus strength, $i$ (photons per square micrometer at $\left.\lambda_{\max }\right)$, and $A_{c}$, the effective collecting area of the outer segment, calculated as by Baylor et al. (1984):

$$
A_{\mathrm{c}}=V_{\mathrm{OS}} Q_{\text {isom }} f 2.303 \alpha \text {, }
$$

where $V_{\mathrm{OS}}$ is the volume of the outer segment; $Q_{\text {isom }}$ is the quantum efficiency of photoisomerization (0.67) (Dartnall, 1972); $f$ is a factor allowing for the use of unpolarized light entering the outer segment perpendicular to its long axis ( $f=0.5$ ); and $\alpha$ is the specific pigment density $\left(0.016 \mu \mathrm{m}^{-1}\right)$ (Bowmaker et al., 1980). Typically stimuli of the optimum wavelength were used; if not, the stimulus strengths were converted to the equivalent number of photons at the optimum wavelength, based on the spectral sensitivity function (see Table 2). The signals from rods were digitized at $4 \mathrm{msec}$ intervals and typically low-pass-filtered at $50 \mathrm{~Hz}$. The signals from cones were digitized at $3 \mathrm{msec}$ intervals and typically lowpass-filtered at $100 \mathrm{~Hz}$.

For seven cells, individual outer segment volume was calculated from digital images of the cells taken during or after recording. The average volume for rods $(n=4)$ was $11.9 \mu \mathrm{m}^{3}$ and for cones $(n=3)$ was 14.3 $\mu \mathrm{m}^{3}$, corresponding to collecting areas of 0.147 and $0.175 \mu \mathrm{m}^{-2}$ respectively. For nine other cells (five rods and four cones), the outer segment volumes and collecting areas were assumed to be similar to the measured means. The small size of mammalian outer segment dimensions and the resolution of the light microscope limit these volume estimates to an accuracy of $\sim 20-30 \%$, based on a linear measurement error of $0.2 \mu \mathrm{m}$. The outer segment of cone photoreceptors is physically fragile but physiologically sturdy; although only a small stub of the OS remained in some cases, high-quality stable recordings were obtained.

For each cell, two to five rising phase responses were simultaneously fit by Equation 1, where $A$ and $t_{\mathrm{d}}$ were allowed to vary to optimize the fitting (Igor; Wavemetrics Inc.). $R_{\max }$ was fixed as the value measured in each cell.

$R N A$ isolation, reverse transcription-PCR, and cDNA cloning. Total RNA was extracted from chipmunk whole retina with retina pigment epithelium using Trizol reagent (Invitrogen, San Diego, CA) by following manufacturer's instructions. Chipmunk RGS9-1, $\mathrm{G}_{\beta 55}$, and cone PDE $\gamma$ cDNAs were cloned by reverse transcription (RT)-PCR and rapid amplification of cDNA ends (RACE) strategies as described previously (Davis et al., 1994). A cDNA fragment encoding amino acids 327-394 within the conserved RGS domain of RGS9-1 was amplified by RT-PCR using degenerate primers cRGS9a, 5'-GGNTT(C/T)TGGGA(A/G)GCNTG(C/ T)GAGA-3'; and cRGS9b, 5'-CAT(A/G)TA(A/G/T)AT(A/G)TGNGT(C/ T)TGNGCNGC(A/G)TC-3'. To obtain the coding sequence on the $5^{\prime}$ end of this fragment, PCR was performed using a degenerate primer, cR5UTR, $5^{\prime}-\mathrm{T}(\mathrm{C} / \mathrm{G} / \mathrm{T})(\mathrm{A} / \mathrm{C})(\mathrm{A} / \mathrm{G}) \mathrm{TCCAGG}(\mathrm{A} / \mathrm{G})(\mathrm{G} / \mathrm{T}) \mathrm{CCAG}-3^{\prime}$, corresponding to the conserved sequence within the $5^{\prime}$ untranslated regions (UTRs) of RGS9-1 from different species, and primer cRNon, 5'-GTAGCGGTGGGGGTG-3', which is reverse complementary to nucleotides encoding amino acids $379-383$. The rest of the coding sequence was amplified by RT-PCR using primer cRCod, 5'-CACGGTGAAGGGGCTGAAG-3', encoding amino acids 373-378; and degenerate primer cRCnon, $5^{\prime}-\mathrm{TTA}(\mathrm{C} /$ T)TTNGGNGGNAG(C/T)TC(C/T)TT-3', designed to be the reverse complement of nucleotides encoding amino acids 479 to stop code, assuming conservation of the last six amino acids with bovine, human, and mouse sequences. A fragment of chipmunk $\mathrm{G}_{\beta 5 \mathrm{~S}}$ cDNA encoding the first 338 amino acids was cloned by RT-PCR using degenerate primers $\mathrm{CGa}, 5^{\prime}$-ATGGCNACNGANGGN(C/T)T-3'; and cGb, 5'AANACNGTNCC(A/G)TCNGG3'. To obtain upstream sequence, RT-PCR was performed using degenerate primer cG5UTR, $5^{\prime}-\mathrm{CCG}(\mathrm{C} / \mathrm{G})(\mathrm{A} / \mathrm{G}) \mathrm{CGAAGATGGC}-3^{\prime}$, which is conserved in $5^{\prime}$ UTRs of $\mathrm{G}_{\beta 5}$; ; and primer cGNon, $5^{\prime}$-GGTCTTCATGACAAACTG-3'. The rest of the coding sequence was obtained by $3^{\prime}$ RACE using primers cG3raceI, 5'-GAGTCTCCATCCTGTTTG-3'; cG3raceII, 5'-GTACTCTACGAGTCTC-3'; and adaptor, 5'-GACTCGAGTCGACATCG- $3^{\prime}$. Chipmunk cone PDE $\gamma$ cDNA was cloned by RT-PCR using degenerate primers cP5UTR, 5'-GCCG(A/C)CC(A/ G)GGGG(A/C)AGT(C/T)AAAATG-3'; and cP3UTR, 5'-TGGCAG$\operatorname{AACC}(\mathrm{C} / \mathrm{T}) \mathrm{CTGG}(\mathrm{C} / \mathrm{T})(\mathrm{A} / \mathrm{G}) \mathrm{CT}-3^{\prime}$. These sequences are conserved in $5^{\prime}$ and $3^{\prime}$ UTRs of mammalian cone PDE $\gamma$.

Sequence data analyses. The chipmunk RGS9-1, $\mathrm{G}_{\beta 5 \mathrm{~S}}$, and cone-type 
PDE $\gamma$ (GenBank accession numbers AF480878, AF480879, and AF480880, respectively) were compared with the corresponding sequences, which were taken from the GenBank or National Center for Biotechnology Information database, with the following accession numbers: mouse (Mus musculus) RGS9-1, AAC99481; $\mathrm{G}_{\beta 5}$, P54314; cone PDE $\gamma$, BAB32255.1; and rod PDE $\gamma$, CAA68714.1; rat (Rattus norveqicus) cone PDE $\gamma$, AAG43400.1; human (Homo sapiens) RGS9-1, AAG09311; $\mathrm{G}_{\beta 5}$, AAC63826; cone PDE $\gamma$, BAA08241.1; and rod PDE $\gamma$, AAA03653.1; bovine (Bos taurus) RGS9-1, O46469; cone PDE $\gamma$, AAA30689.1; and rod PDE $\gamma$, CAA28507.1; tiger salamander (Ambystoma tigrinum) $\mathrm{G}_{\beta 5}$, AAK52836.1; fruit fly (Drosophila melanogaster) $\mathrm{G}_{\beta 5}$, AAF46336; nematode (Caenorhabditis elegans) $\mathrm{G}_{\beta 5}$, AC Q20636; 13-lined ground squirrel (Spermophilus tridecemlineatus) cone PDE $\gamma$, CAA04720.1; leopard frog (Rana pipiens) cone PDE $\gamma$, AAK95403.1; and rod PDE $\gamma$, AAK95404.1; guinea pig (Cavia porcellus) rod PDE $\gamma$, AAG43274.1; and dog (Canis familiaris) rod PDE $\gamma$, CAA93815.1. The sequences were aligned, and phylogenetic trees were constructed by CLUSTALW (Thompson et al., 1994) based on the neighbor-joining method (Saitou and Nei, 1987).

Protein expression and purification. Chipmunk RGS9-1 and PDE $\gamma$ and mouse RGS9-1 cDNAs were subcloned into the pET-14b expression vector (Novagen, Madison, WI) using NdeI and BamHI restriction sites. $\mathrm{His}_{6}{ }^{-}$tagged recombinant proteins were purified using a $\mathrm{Ni}^{+}$-nitrilo triacetic acid column (Qiagen, Hilden, Germany) by following the manufacturer's instructions using denaturing conditions. His 6 -tagged chipmunk PDE $\gamma$ was further purified by reverse-phase HPLC as described previously (Angleson and Wensel, 1994). Endogenous bovine rod PDE $\gamma$ was purified from the bovine rod outer segment (ROS) following procedures described previously (Wensel and Stryer, 1990). In each case, the concentration of purified protein was determined by absorbance at 280 $\mathrm{nm}$ in $6 \mathrm{~m}$ guanidinium chloride using extinction coefficients calculated from the sequence (Gill and von Hippel, 1989).

Immunofluorescence staining. Immunofluorescence staining of mouse and chipmunk RGS9-1 and $\mathrm{G}_{\beta 5}$ was performed according to the procedure described previously (Lyubarsky et al., 2001). To stain chipmunk RGS9-1 and rhodopsin, chipmunk eyes were fixed in 4\% paraformaldehyde and PBS, $\mathrm{pH} 7.2$, for $10-16 \mathrm{hr}$ at $4^{\circ} \mathrm{C}$. After protection in $30 \%$ sucrose and PBS for $1 \mathrm{hr}$ at $4^{\circ} \mathrm{C}$, the eyes were embedded in OCT compound (Tissue-Tek), and frozen sections were cut at $16 \mu \mathrm{m}$. Tissue sections were postfixed in 1:1 methanol/acetone $(\mathrm{v} / \mathrm{v})$ for $10 \mathrm{~min}$ at room temperature and rehydrated in PBS, pH 7.2, for 20 min at room temperature. Nonspecific binding was blocked by incubating the sections for 1 $\mathrm{hr}$ at room temperature with $10 \%$ sheep serum (Sigma, St. Louis, MO) and PBS. Then the sections were incubated with primary antibody to RGS9, anti-RGS9-1c (He et al., 1998), at a 1:200 dilution, and antirhodopsin monoclonal antibody, 1D4 (Wu et al., 1998), at a 1:500 dilution in $10 \%$ sheep serum and PBS. The sections were incubated with primary antibodies at room temperature overnight in a humidified atmosphere. After being washed three times for $5 \mathrm{~min}$ in PBS at room temperature, sections were incubated with secondary antibodies, fluorescein isothiocyanate-conjugated anti-rabbit IgG (Vector Laboratories, Burlingame, CA) and rhodamine-conjugated anti-mouse IgG (Vector Laboratories), at a 1:100 dilution, in 10\% sheep serum and PBS for $1 \mathrm{hr}$ at room temperature in a humidified atmosphere. Sections were washed three times for $10 \mathrm{~min}$ in PBS at room temperature and mounted in aqueous mounting medium (Gel/Mount; Biomeda, Foster City, CA). Sections were examined and images recorded using a Zeiss (Thornwood, NY) 510 LSM confocal microscope.

Preparation of retina extracts. All procedures were performed in complete darkness or under infrared light. Because of the extracellular matrix structures known as cone sheaths, chipmunk retina is not easily peeled from the underlying layer of retinal pigmented epithelium (RPE) without substantial loss of cone outer segments. Also, previous studies have shown that the proteins of interest are not expressed at detectable levels in RPE; therefore, we homogenized a sample of retina plus RPE to maximize the yield of cone-derived material. One chipmunk retina with attached retinal pigmented epithelium, two mouse retinas, and $100 \mu \mathrm{g}$ of bovine retina were homogenized in $600 \mu \mathrm{l}$ of buffer A. After centrifugation for $15 \mathrm{~min}$ at $80,000 \times \mathrm{g}$, the pellets were resuspended in $300 \mu \mathrm{l}$ of buffer A supplemented with $3 \mu \mathrm{l}$ of $4 \mathrm{~mm}$ ethanol solution of 11-cis- retinal and incubated at $4^{\circ} \mathrm{C}$ for $2 \mathrm{hr}$. Retina pellets were recovered by centrifugation again for $15 \mathrm{~min}$ at $80,000 \times \mathrm{g}$ and incubated in buffer $\mathrm{A}$ supplemented with $1 \% 3$-[(3-cholamidopropyl)dimethylammonio]-1propanesulfonate for $30 \mathrm{~min}$ at $4^{\circ} \mathrm{C}$. Supernatants containing extracted membrane and soluble proteins were obtained by centrifugation for 15 $\min$ at $10,000 \times g$.

Spectroscopic measurements. The UV-visible absorption spectra of detergent-solubilized retina extracts were recorded with an HP 8452A spectrophotometer in cuvettes of $1.0 \mathrm{~cm}$ path length at room temperature. Spectra were recorded before and after illumination of samples for 3 min with a $150 \mathrm{~W}$ light bulb (Reflector Flood; Philips). Hydroxylamine-hydrochloride, $\mathrm{pH}$ 7.0, was added to a final concentration of $20 \mathrm{~mm}$ after the samples were illuminated, and the spectra were recorded again. Difference spectra were obtained by subtracting the spectrum after bleaching from that before illumination. Absorbance values were all within the linear response range of the spectrophotometer. To generate the model spectra for rods and M-cones, the Dawis (1981) polynomials were used in a two-parameter least squares fit varying the $\log$ of maximum sensitivity, $b_{\max }$, and peak wavelength, $\lambda_{\max }$. To generate estimates of extinction coefficients, the sensitivity values at each wavelength were normalized by dividing by $10^{\mathrm{bmax}}$ and then multiplied by $40,000 \mathrm{M}^{-1} \cdot \mathrm{cm}^{-1}$ (Vissers et al., 1998). For the S-cone sensitivity data and for the M-cone data for wavelengths $<450 \mathrm{~nm}$, in which the Dawis polynomial fits poorly, the data were fit to Gaussian curves, $S(\lambda)=$ $a_{\mathrm{o}}+\left(S\left(\lambda_{\mathrm{c}}\right)-a_{\mathrm{o}}\right) \exp \left[-\left(\lambda-\lambda_{\mathrm{c}}\right)^{2} / 2 w^{2}\right]$, to provide a smooth curve declining monotonically with distance from $\lambda_{\mathrm{c}}$ and closely approximating the sensitivity data (Ditchburn, 1963; Harris and Bertolucci, 1978), and the extinction coefficients were calculated as $\epsilon(\lambda)=S(\lambda) \cdot 40,000$ $\mathrm{M}^{-1} \cdot \mathrm{cm}^{-1} / S\left(\lambda_{\mathrm{c}}\right)$. The assumptions are that the extinction coefficients $\epsilon(\lambda)$ are proportional to the sensitivities $S(\lambda)$ with a constant proportionality constant for each cell type and pigment, and that the extinction coefficient $\epsilon\left(\lambda_{\max }\right.$ or $\left.\lambda_{\mathrm{c}}\right)$ at the wavelength of maximal sensitivity ( $\lambda_{\max }$ or $\lambda_{\mathrm{c}}$ ) is equal to $40,000 \mathrm{M}^{-1} \cdot \mathrm{cm}^{-1}$. Values found by fitting were as follows: rods, $L_{\max }=502 \mathrm{~nm} ; \lambda_{\max }=500.36 \mathrm{~nm}$; and $b_{\max }=0.0058$ $\left(b_{\max }=0\right.$ assigned to maximal measured value tabulated in Table 2); M-cones, $L_{\max }=562 \mathrm{~nm} ; \lambda_{\max }=537.48 \mathrm{~nm} ; b_{\max }=0.0066 ; a_{\mathrm{o}}=$ $0.21384 ; S\left(\lambda_{\mathrm{c}}\right)=1.126 ; \lambda_{\mathrm{c}}=538.78 \mathrm{~nm}$; and $w=44.34 \mathrm{~nm}$; and $\mathrm{S}$-cone, $a_{\mathrm{o}}=-0.0206 ; S\left(\lambda_{\mathrm{c}}\right)=1.324 ; \lambda_{\mathrm{c}}=452.8 \mathrm{~nm}$; and $w=58.49 \mathrm{~nm}$. The difference spectrum was fit to a linear combination of the model spectra in the range of 400-600 $\mathrm{nm}$ using the Levenberg-Marquardt (Levenberg, 1944; Marquardt, 1963) least squares algorithm as implemented in the program Origin and the equation $\Delta A(\lambda)=m \epsilon_{\mathrm{m}}(\lambda)+r \epsilon_{\mathrm{r}}(\lambda)+$ $s \epsilon_{\mathrm{s}}(\lambda)-(m+r+s) \epsilon_{\mathrm{R}} *(\lambda)$. Here $m, r$, and $s$ are the molar concentrations of M-cone pigment, rhodopsin, and S-cone pigment, respectively; $\epsilon_{\mathrm{m}}(\lambda)$, $\epsilon_{\mathrm{r}}(\lambda)$, and $\epsilon_{\mathrm{s}}(\lambda)$ are the corresponding model spectra from Figure $3 A$; and $\epsilon_{\mathrm{R}} *(\lambda)$ is the metarhodopsin II spectrum shown in Figure $3 A$.

Immunoblotting and densitometry. After spectrophotometry to quantify visual pigments, chipmunk, mouse, and bovine retina detergent extracts and bovine ROS were analyzed by SDS-PAGE, followed by immunoblotting and densitometry. Immunoblotting was performed according to a standard protocol (Harlow and Lane, 1988) on proteins separated by SDS-PAGE. Buffer B was used for electrophoretic transfer of PDE $\gamma$, and buffer B supplemented with $0.1 \%$ SDS was used for transfer of RGS9-1 and $G_{\beta 5}$. The membranes for immunoblotting were supported nitrocellulose (NitroPure; Osmonics, Inc.). After $60 \mathrm{~min}$ for RGS9-1 and $\mathrm{G}_{\beta 5}$ or $45 \mathrm{~min}$ for PDE $\gamma$ transfer at $350 \mathrm{~mA}$ at $4^{\circ} \mathrm{C}$, membranes were blocked by $5 \%$ nonfat dry milk and a solution of $20 \mathrm{~mm}$ Tris- $\mathrm{HCl}, \mathrm{pH} 7.2$, $150 \mathrm{~mm} \mathrm{NaCl}$, and $0.1 \%$ (v/v) Tween 20 for $1 \mathrm{hr}$, followed by incubation with primary antibody for $4 \mathrm{hr}$. Polyclonal antibodies anti-RGS9-1 $\mathrm{c}$ and anti- $G_{\beta 5}$ (He et al., 2000) were used at a 1:1000 dilution, and anti-PDE $\gamma$ was used at a dilution of 1:500. The secondary antibody used was horseradish peroxidase-conjugated anti-rabbit IgG (Promega, Madison, WI), with detection by chemiluminescence using the ECL system (Amersham Biosciences, Arlington Heights, IL). For densitometry of chemiluminescence signals on film, $\mathrm{x}$-ray films were scanned, and bands were quantified by software UN-SCAN-IT (Silk Scientific Corp.). To quantify RGS9-1 and PDE $\gamma$ or to calibrate antibody specificity, purified recombinant proteins and highly purified PDE $\gamma$ from bovine retina were used as standards. The concentrations of purified proteins were determined by 
spectrophotometry at $280 \mathrm{~nm}$ as described above or by using densitometry of Coomassie blue-stained bands on SDS-PAGE gels calibrated with standards whose concentrations were determined by $280 \mathrm{~nm}$ absorbance. On each gel, varying amounts of standard protein were loaded next to different volumes of the retinal extract. Films were exposed to the blots after processing for chemiluminescence detection, with varying exposure times to ensure that film optical density was linear with the protein amount for standards whose values of optical density bracketed those of the corresponding bands from the extracts. The optical density of the band in question from each extract lane was then substituted into the linear function (derived by least squares fitting) for density, to solve for the amount of specific protein in each extract sample. Dividing this amount by the volume loaded gave a value of concentration for each sample, and these were averaged. In some cases, the blot was initially performed with a standard from another species (e.g., bovine PDE $\gamma$ ), and then later, the relative sensitivity of the antibody for the protein of the species in question (e.g., chipmunk)

was determined using blots with purified recombinant proteins from both species (e.g., bovine and chipmunk) to obtain correction factors. The correction factors were determined as the ratios of calculated amounts of protein from Western blots and densitometry to the amounts of each purified protein (determined by spectrophotometry) loaded on SDS-PAGE (see Figs. $6 B, 7 C, D$ ). The correction factor for chipmunk cone PDE $\gamma$ detection by anti-PDE $\gamma$ is 0.79 . The correction factors of anti-RGS9-1c for chipmunk and mouse RGS9-1 are 0.97 and 1.97, respectively.

Immunoprecipitation. Purified anti-RGS9 antibody anti-RGS9-1c was covalently attached to cyanogen bromide-activated Sepharose 4B-CL as described previously (Hu et al., 2001). For immunoprecipitation, chipmunk or bovine retina was homogenized and solubilized with $200 \mu \mathrm{l}$ of buffer A supplemented with $1 \%$ Nonidet P-40. The insoluble material was removed by centrifugation for $15 \mathrm{~min}$ at $80,000 \times \mathrm{g}$. The solubilized retina extracts were incubated with $10 \mu \mathrm{l}$ of anti-RGS9-1c IgG-coupled beads for $10-16 \mathrm{hr}$ at $4^{\circ} \mathrm{C}$ after mixing on a shaker. The beads were separated from supernatant by a brief centrifugation and washed three times with the solubilization buffer. Bound proteins were redissolved in the SDS-PAGE sample buffer and separated from the beads by a brief centrifugation.

PDE assays. PDE catalytic activity was measured with the $\mathrm{pH}$ recording method (Liebman and Evanczuk, 1982) as modified previously (Malinski and Wensel, 1992). Specifically, assays were performed in buffer $C$ with initial cGMP concentration of $2 \mathrm{~mm}$ and a total volume of $200 \mu$ l. Assays were performed in 96-well microtiter plates and monitored with MI-410 microelectrodes (Microelectrodes, Inc.). To test chipmunk cone PDE and bovine rod PDE activity, each assay was initiated by adding $15 \mu \mathrm{l}$ of chipmunk retina homogenate or $10 \mu \mathrm{l}$ of bovine ROS, which had 0.4 pmol of PDE calculated from PDE $\gamma$ quantitative immunoblots, and maximal PDE activation was obtained by adding 30 $\mu \mathrm{g}$ of trypsin (Sigma) to remove inhibitory subunit PDE $\gamma$. After PDE was fully activated, $300 \mu \mathrm{g}$ of soybean trypsin inhibitor (Sigma) was added to quench trypsin. Then PDE activity was blocked by adding $0.2 \mathrm{nmol}$ of $\mathrm{His}_{6}$-tagged bovine PDE $\gamma$ and restored by adding $300 \mu \mathrm{g}$ of trypsin again. To test chipmunk cone PDE $\gamma$ and bovine $\operatorname{rod} \operatorname{PDE} \gamma$ inhibitory activity, bovine PDE was purified and treated with trypsin as described previously (Wensel and Stryer, 1990). Each assay was performed in 200 $\mu \mathrm{l}$ of buffer $\mathrm{C}$ with $2 \mathrm{~mm}$ cGMP, and the $\mathrm{pH}$ recordings were initiated when trypsin-treated PDE was added to a final concentration of $5 \mathrm{~nm}$. After the reactions had proceeded $\sim 1 \mathrm{~min}$, $\mathrm{His}_{6}$-tagged bovine rod or chipmunk cone PDE $\gamma$ was added to different concentrations of $0,2,4$, and $8 \mathrm{~nm}$. To test chipmunk cone PDE $\gamma$ inhibitory activity on chipmunk
RGS9-1
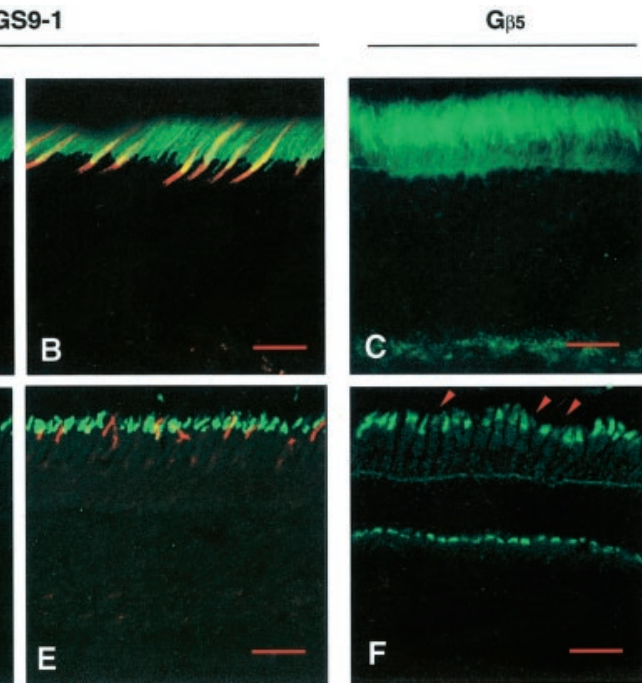

os

IS

ONL

OPL

os

IS

ONL

OPL

E

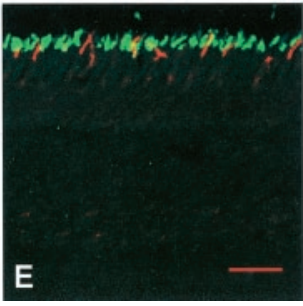

\section{(2)} $150 \mu \mathrm{l}$ of the homogenate was treated by $150 \mu \mathrm{g}$ of trypsin at room temperature for $1 \mathrm{~min}$, followed by $1.5 \mathrm{mg}$ of soybean trypsin inhibitor. Each $\mathrm{pH}$ assay was performed in a final volume of $200 \mu \mathrm{l}$ of buffer $\mathrm{C}$ with $2 \mathrm{~mm}$ cGMP. The recordings started when $40 \mu \mathrm{l}$ of trypsin-treated chipmunk retina homogenate $(\sim 0.4 \mathrm{pmol}$ of PDE) was added. After the reactions had proceeded $\sim 1$ min, His $_{6}$-tagged chipmunk cone PDE $\gamma$ was added to different concentrations of 1,2, and 4 nM.

GTPase single turnover assays. GTPase single turnover assays were performed to test the bovine rod or chipmunk cone PDE $\gamma$ RGS9-1 GTPaseaccelerating protein (GAP) enhancement effect, essentially as described previously (He et al., 2000). Specifically, bovine rod outer segments containing $10 \mu \mathrm{M}$ rhodopsin were exposed to light and mixed with different amounts $(0,10,20,50$, or $100 \mathrm{~nm})$ of $\mathrm{His}_{6}$-tagged bovine rod or $\mathrm{His}_{6}$ tagged chipmunk cone PDE $\gamma$ in buffer D. Then GTP hydrolysis was initiated by adding $7 \mu \mathrm{l}$ of $\left[\gamma^{-32}{ }^{32} \mathrm{P}\right] \mathrm{GTP}$ (Amersham Biosciences) to $14 \mu \mathrm{l}$ of the above mixture by vortexing. The reaction was quenched by $100 \mu \mathrm{l}$ of $5 \%$ trichloroacetic acid at various times, and $\mathrm{P}_{\mathrm{i}}$ (free phosphate ion) released from hydrolyzed GTP was determined by activated charcoal assay. The first-order rate constants for GTP hydrolysis $\left(k_{\text {inact }}\right)$ were obtained by fitting data to single exponentials.

\section{Results}

Immunostaining of RGS9-1 and $\mathrm{G}_{\beta 5}$ in mouse and chipmunk retinas

RGS9-1 immunofluorescence was observed primarily in outer segments of photoreceptor cells (Fig. $1 A, B, D, E$ ). In roddominant mouse retina, much brighter immunofluorescence was observed in cone outer segments, identified by staining of cone sheaths with rhodamine-conjugated peanut agglutinin. In cone-dominant chipmunk retina, cone outer segments were stained brightly, whereas RGS9-1 staining in rod outer segments, identified by staining with anti-rhodopsin antibody 1D4, was barely detectable. These results, together with previous results in bovine and human retinas (Cowan et al., 1998; Zhang et al., 1999) confirm that in mammals, much more RGS9-1 is present in cone outer segments than in rods, and that most RGS9-1 in chipmunk retina is in cone outer segments.

Strong $\mathrm{G}_{\beta 5}$ staining (Fig. 1C,F) was observed in photoreceptor outer segments. The $\mathrm{G}_{\beta 5}$ staining of the multiple chipmunk rods present in each field was so weak as to be undetectable, 
whereas the cones stained brightly (Fig. $1 F$ ). There is also staining in what appear to be the photoreceptor synaptic termini in the outer plexiform layer. The function of $\mathrm{G}_{\beta 5}$ in this region of the cells remains to be determined. Because RGS9-1 staining is not observed in the outer plexiform layer, any $\mathrm{G}_{\beta 5}$ there is unlikely to be associated with RGS9-1.

\section{Photoresponses of chipmunk cones}

Suction electrode recordings were made from chipmunk rod and cone cells to define the differences in their sensitivity and the kinetics of the recovery phase of their light response as well as to determine the action spectra. Figure 2 shows families of photocurrent responses in a rod (Fig. $2 A$ ) and M-cone (Fig. 2B) to brief light flashes of increasing intensity. The average time to peak of the linear range responses in the rods was 2.25 times slower than in M-cones (Table 1). The graphs on the right of Figure 2, A and $B$, plot the peak response amplitude versus the log-stimulus intensity. The smooth curves are fits to the data with an exponential saturation function of the type used by Lamb et al. (1981). There was a 38 -fold difference in the sensitivity as measured by $I_{1 / 2}$ (the stimulus strength required to produce a half-maximal response) or 140-fold difference as measured by the flash sensitivity $\left(S_{\mathrm{f}}\right.$, picoamperes per photon per square micrometer), which is measured for linear range responses (Table 1).

Use of RGS9-1 staining to identify cones and 1D4 staining to identify rods allowed counting of rods and cones in the chipmunk sections. In eight fields counted, cones made up an average of $75.0 \pm 2.6 \%$ of the total photoreceptors; if we account for the slightly higher probability of finding cones in an optical section because of their $\sim 11 \%$ greater width, this value becomes $68 \%$. Of the 15 cones studied electrophysiologically, two were S-cones; the remainder were $\mathrm{M}$-cones. Eleven of $13 \mathrm{M}$-cones and 0 of 2 $\mathrm{S}$-cones had an undershoot in the recovery phase of the response.

The efficiencies of signal amplification in the transduction cascade in different cell types can be compared by fitting the rising phases of the responses to Equation 1, which models the activation reactions only, and then comparing the values of $A$, or gain. Results of the model fitting to multiple responses are shown for one rod (Fig. 2C) and one cone (Fig. 2D). The mean values for 16 chipmunk rod and cone cells are given in Table 1. The gain for cones had a mean value of $1.0 \mathrm{sec}^{-2}$, and a range of $0.3-1.7 \mathrm{sec}^{-2}$. Similar results were obtained when the same analysis was applied to previously published results of human cone (Kraft et al., 1998, their Fig. 1; $A=0.9 \mathrm{sec}^{-2}$ ) and ground squirrel cone (Kraft, 1988, Fig. $3 a, b ; A=1.0$ and $1.7 \mathrm{sec}^{-2}$, respectively). Chipmunk rods had a mean gain of $10.4 \mathrm{sec}^{-2}$ with a range of $6.2-14.2 \mathrm{sec}^{-2}$. Although there is some variability from cell to cell for both rods and cones, the average values indicate an order of magnitude lower amplification, as reflected in the parameter $A$, in cones of all three species compared with chipmunk rods.

To achieve some appreciation for the difference in the recovery kinetics of the photoresponses, a simple linear regression of the photocurrent recovery was performed covering saturating and semisaturating responses. The recovery kinetics were also significantly faster in cones than in rods. As indicated in Table 1, the slopes of the recovery phases (picoamperes per second) for the cones were 3.1- to 4.5 -fold steeper than those of rods, with both normalized to the maximum photocurrent in each cell.

The action spectra of the rod and cone visual pigments were measured by determining the stimulus strength that was required to generate a criterion linear range response. The results are presented in Table 2 and graphically in Fig. 3A. S- and M-cones were encountered with peak sensitivities of $\sim 450$ and $540 \mathrm{~nm}$, respec-
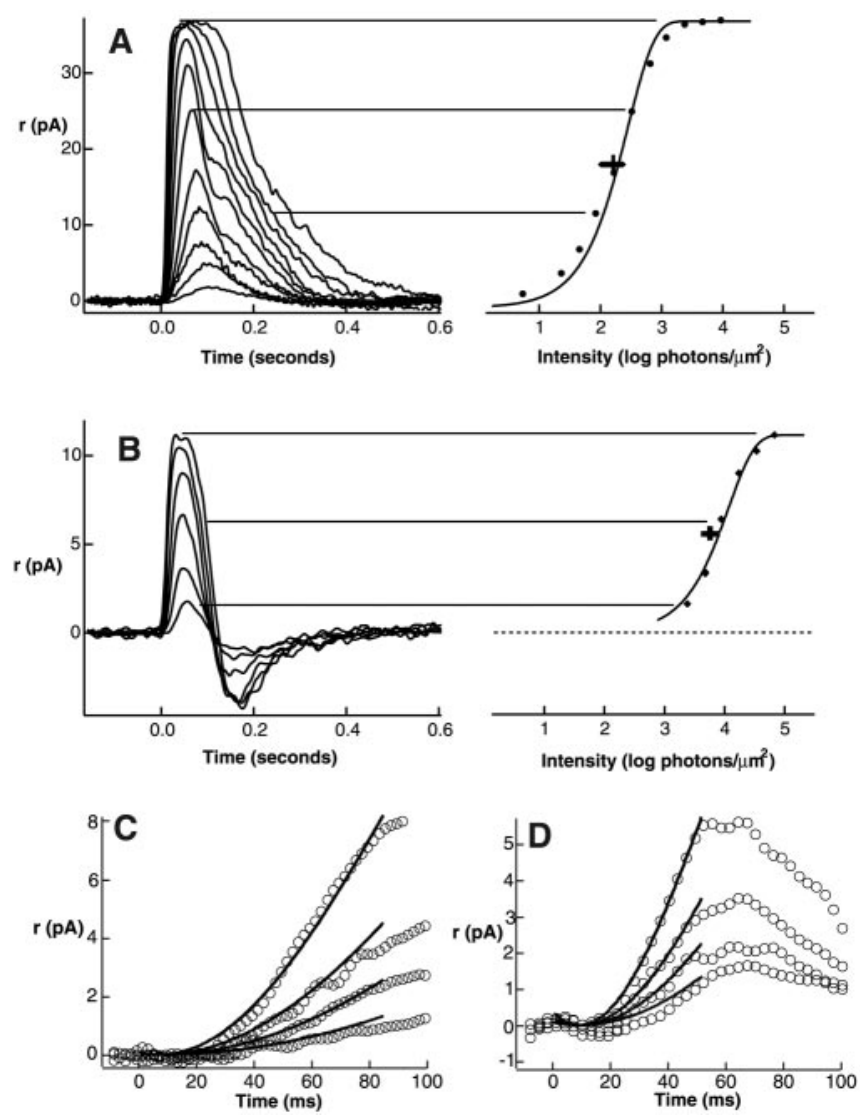

Figure 2. Suction electrode recordings of the light-evoked currents from chipmunk rod and cone photoreceptors. A, Rods. A family of responses evoked by $2 \mathrm{msec}$ flashes of light of increasing strength. Each trace represents the averaged response of 3-39 repeated stimuli ( $D C$ to 50 $\mathrm{Hz}, 37^{\circ} \mathrm{C}$ ). The stimulus strength varied from 0.73 to $3.97 \mathrm{log}$-photons $/ \mu \mathrm{m}^{2}$ (or $5.4-9200$ photons $\left./ \mu \mathrm{m}^{2}\right)$. On the right, the peak amplitude of each response is plotted against the log of the stimulus strength. The long thin lines between the left and right graphs connect selected data points with their respective photocurrent traces. The smooth curve is an exponential saturation function fit to the intensity response data (see Results). The short vertical bar near the middle of the intensity graph indicates the mean value of $I_{1 / 2}$ for 30 rods; the short horizontal bar indicates $\pm 1 S D$. $B$, Cones. Left, Family of responses recorded from a cone; each trace is the average of 5-20 responses to stimuli whose strength ranged from 3.38 to 4.83 log-photons/ $\mu \mathrm{m}^{2}$ (or $2410-67,200$ photons $/ \mu \mathrm{m}^{2}$; DC to $100 \mathrm{~Hz}, 36^{\circ} \mathrm{C}$ ). Right, Intensity-versus-response plot for the cone data fit by an exponential saturation function. The short vertical bar near the middle of the intensity graph indicates the mean value of $I_{1 / 2}$ for $11 \mathrm{M}$-cones; the short horizontal bar indicates \pm 1 SD. C, Fitting of the equation of Lamb and Pugh (1992) (Equation 1) to responses of a typical rod, over the period from 0 to $85 \mathrm{msec}$ after the flash. Photoisomerizations for the four traces were $\Phi=1.5,3.0,5.6$, and 11.1 , and $\mathrm{R}_{\max }=26 \mathrm{pA}$ in this cell. Parameters obtained from the fit were gain, $A=11.3 \mathrm{sec}^{-2}$; and delay, $t_{\mathrm{d}}=7.6 \mathrm{msec}$. $D$, Fitting of the same equation to responses of a typical $\mathrm{M}$-cone over the period from 0 to $52 \mathrm{msec}$ after the flash. Photoisomerizations for the four traces were $\Phi=61.9,108,176$, and 319 , and $\mathrm{R}_{\max }=15 \mathrm{pA}$ in this cell. Parameters obtained from the fit were gain, $A=1.7 \mathrm{sec}^{-2}$; and delay, $t_{\mathrm{d}}=9.8$ msec.

tively. The rod peak sensitivity was $504 \mathrm{~nm}$; no L-cones were encountered. Behavioral testing of the cone-mediated vision found the threshold difference between 539 and $580 \mathrm{~nm}$ of 0.231 $\log$ units (R. E. Van Arsdel and M. S. Loop, personal communication), an excellent match of the action spectra sensitivity differences for the $\mathrm{M}$-cones from single-cell recordings at similar wavelengths ( $0.239 \log$ units for $541 \mathrm{vs} 580 \mathrm{~nm}$; Table 2).

Cloning of chipmunk RGS9-1, $\mathrm{G}_{\beta 5}$, and cone PDE $\gamma$ cDNAs Chipmunk RGS9-1, G $_{\beta 55}$, and PDE $\gamma$ cDNAs were cloned from chipmunk retina via RT-PCR and RACE; sequences are available 
Table 1. Properties of chipmunk photoreceptors

\begin{tabular}{|c|c|c|c|}
\hline Value & Rods & M-cones & S-cones \\
\hline$I_{\max }(\mathrm{pA})$ & $18.0 \pm 1.5(29)$ & $9.2 \pm 0.6(13)$ & $7.4 \pm 2.3(2)$ \\
\hline$I_{1 / 2}\left(\right.$ photons $\left./ \mu \mathrm{m}^{2}\right)$ & $153 \pm 18(29)$ & $5806 \pm 946(11)$ & $3500 \pm 2100(2)$ \\
\hline Time to peak (msec) & $116 \pm 6(27)$ & $52 \pm 2.9(11)$ & $64 \pm 20(2)$ \\
\hline Integration time (msec) & $183 \pm 18(27)$ & $31 \pm 5.5(11)$ & $83 \pm 4.3(2)$ \\
\hline$S_{f}\left(p A \cdot\right.$ photon $\left.^{-1} \cdot \mu m^{-2}\right)$ & $0.126 \pm 0.002(27)$ & $0.00091 \pm .00034(11)$ & $0.00155 \pm 0.00064(2)$ \\
\hline Recovery slope saturating response (normalized pA/sec) & $-5.12 \pm 0.71(19)$ & $-15.8 \pm 1.1(12)$ & $-14.7 \pm 8.5(2)$ \\
\hline Recovery slope semisaturating (normalized pA/sec) & $-2.21 \pm 0.38(18)$ & $-10.0 \pm 0.8(12)$ & $-9.8 \pm 7.8(2)$ \\
\hline$A\left(\sec ^{-2}\right)$ & $10.4 \pm 0.90(9)$ & $1.04 \pm 0.25(5)$ & $1.03 \pm 0.58(2)$ \\
\hline
\end{tabular}

Each value is the mean \pm SEM, and the number of observations is given in parentheses. Integration time is the integral of the photocurrent response divided by the peak amplitude (after Baylor and Hodgkin, 1973). The recovery slope is linear fit to the recovery phase of the photocurrent response covering $25-75 \%$ of the response. $A$ is the gain factor for the rising phase of phototransduction cascade determined by fitting the equation of Lamb and Pugh (1992) to multiple responses from each cell. $I_{1 / 2}$ is the stimulus strength at the optimum wavelength that will generate a half-maximum response.

from GenBank with accession numbers listed in Materials and Methods. The cloned chipmunk RGS9-1 cDNA includes part of the 5' UTR and coding sequence corresponding to first 478 of 484 amino acids. The rest of the coding sequence was cloned by degenerate PCR on the basis of the assumption that the last six amino acids are conserved among mammalian RGS9-1. The deduced amino acid sequence of chipmunk RGS9-1 shares $>90 \%$ identity with human, mouse, and bovine RGS9-1 (Fig. 4A). By RT-PCR, chipmunk cone PDE $\gamma$ CDNA was cloned, using two degenerate primers conserved in the $5^{\prime}$ and 3' UTR of mammalian cone PDE $\gamma$. The deduced amino acid sequence of chipmunk PDE $\gamma$ has $95 \%$ identity to bovine, mouse, ground squirrel, and human cone PDE $\gamma$ and $78 \%$ identity to
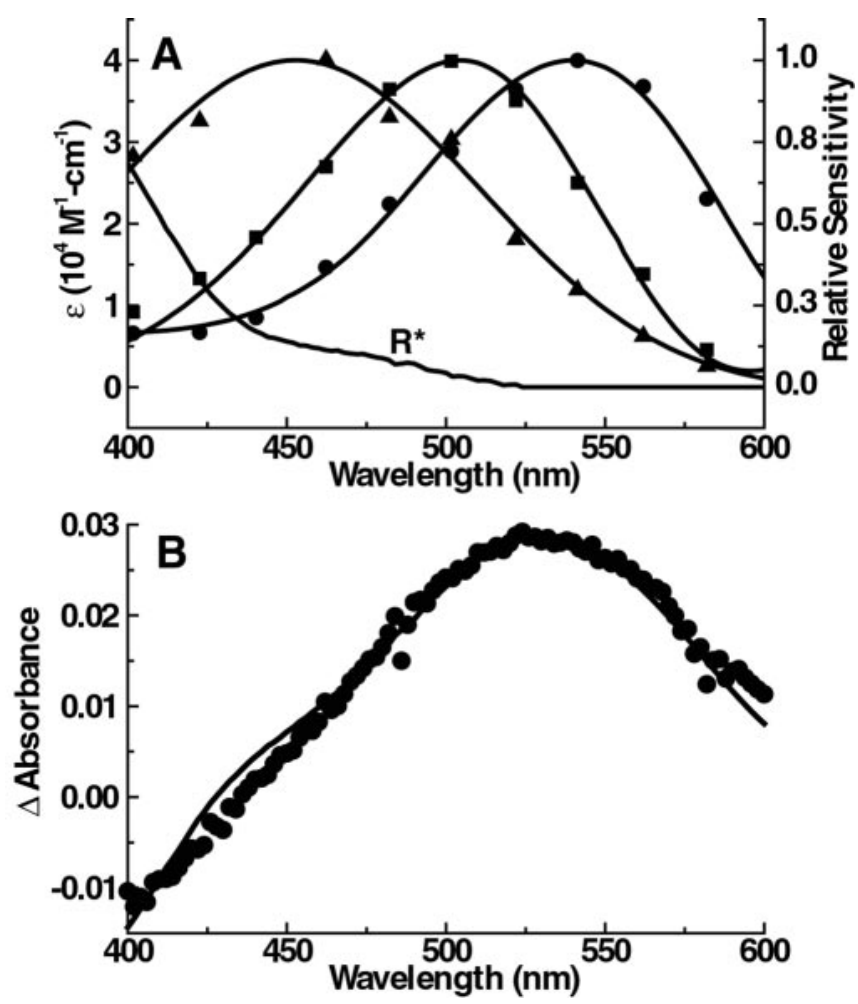

Figure 3. Estimation of pigment content by difference spectrophotometry. $A$, Model absorbance spectra used for estimates. Relative spectral sensitivity data, determined from suction electrode current recordings as described in Results, are shown along with curves representing the model spectra fit to the data as described in Materials and Methods. Circles, M-cones; squares, rods; triangles, $\mathrm{S}$-cones. The solid line labeled $R^{*}$ is a plot of measured absorbance data for bovine rhodopsin after illumination. $B$, Difference spectrum of detergent extract of chipmunk retina-RPE. Circles, Difference between absorbance before and after exposure to room light; line, fit of linear combination of model spectra to difference spectrum. The curve is the result predicted for a molar ratio of $\mathrm{M}$ pigment/rhodopsin/S pigment of 1:0.30:0.05 and a total cone pigment concentration of $0.60 \mu \mathrm{m}$. bovine, human, mouse, and dog rod PDE $\gamma$ (Fig. 4C). Chipmunk $\mathrm{G}_{\beta 5 \mathrm{~S}} \mathrm{CDNA}$ was also cloned from chipmunk retina RNA by RT-PCR and RACE. The deduced amino acid sequence is $100 \%$ identical to that of mouse $\mathrm{G}_{\beta 5 \mathrm{~S}}$ (Fig. $4 B$ ).

\section{Catalytic activity of chipmunk cone PDE}

To measure the efficiencies of hydrolysis of cGMP by PDE in mammalian cones and compare the results with those in rods, we performed $\mathrm{pH}$-based $\mathrm{PDE}$ assays in homogenates from cone-dominant chipmunk retina and bovine ROS. Figure $5 \mathrm{~A}$ shows $\mathrm{pH}$ recordings in bovine or chipmunk samples containing $4 \mathrm{nM}$ endogenous PDE $\gamma$. Both chipmunk cone and bovine rod PDE displayed low basal activity and were similarly activated by addition of trypsin to remove the inhibitory subunit PDE $\gamma$, and the activation was reversed by adding back $\mathrm{His}_{6}$-tagged bovine rod PDE $\gamma$ after the addition of soybean trypsin inhibitor. Basal and maximal PDE activities in chipmunk retinal homogenates were similar to those in bovine samples. The concentration of PDE in each of the samples was calculated to be 2 nM from PDE $\gamma$ immunoblots, using the ratio of two PDE $\gamma$ subunits per holoPDE heterotetramer. On the basis of this concentration and the observed catalytic activity, the calculated maximum turnover numbers for chipmunk and bovine PDE were 3600 and $3900 \mathrm{~mol}$ of cGMP hydrolyzed per mole of PDE per second, respectively. These numbers are consistent with a previously reported rod PDE $k_{\text {cat }}$ value of $\sim 4000$ cGMP hydrolyzed per PDE per second (Hurley and Stryer, 1982; Stryer et al., 1983), indicating chipmunk cone PDE and bovine rod PDE have similar cGMP hydrolytic activities when fully activated. Bovine cone PDE has been reported to have a similar specific activity of 3500-4670 cGMP per second (Gillespie and Beavo, 1988).

Biochemical properties of chipmunk cone PDE $\gamma$

To test the potency of PDE inhibition by chipmunk cone PDE $\gamma$, $\mathrm{pH}$ assays were performed using $5 \mathrm{~nm}$ trypsin-treated bovine PDE or 2 nM chipmunk PDE, and varying concentrations of bovine $(0$, 2, 4, and $8 \mathrm{nM}$ ) or chipmunk (0, 1, 2, 4, and $8 \mathrm{nM}) \mathrm{His}_{6}$-PDE $\gamma$ (Fig. $5 B)$. Hydrolysis of cGMP slowed dramatically within seconds of addition of recombinant $\operatorname{PDE} \gamma$. cGMP hydrolytic velocity, $d[\mathrm{cGMP}] / d t$, was determined from the slope at each point along the $\mathrm{pH}$-recording traces (Fig. $5 B$, top). PDE $\gamma$ inhibitory activity toward trypsin-activated PDE was determined by the difference in hydrolytic velocity before and after addition of PDE $\gamma$. Figure $5 B$, bottom, shows that chipmunk cone and bovine rod PDE $\gamma$ have similar inhibitory effects on bovine rod PDE. The PDE $\gamma$ inhibitory activities were calculated from linear least squares fits. When added to bovine rod PDE, each mole of bovine rod PDE $\gamma$ inhibited hydrolysis of $1773 \pm 207$ (mean \pm SD) mol of cGMP per second, and each mole of chipmunk cone PDE $\gamma$ inhibited hydrolysis of $1620 \pm 275 \mathrm{~mol}$ of cGMP per second. When added 
Table 2. Spectral sensitivity of the chipmunk photoreceptors as determined by single-cell recordings

\begin{tabular}{|c|c|c|c|c|c|c|c|}
\hline \multirow[b]{2}{*}{$\lambda(\mathrm{nm})$} & \multicolumn{3}{|l|}{ Rods } & \multicolumn{3}{|l|}{ M-cones } & \multirow[b]{2}{*}{ S-cone } \\
\hline & $\log S$ & SE & $n$ & $\log S$ & SE & $n$ & \\
\hline 380.0 & -0.770 & 0.053 & 5 & -0.776 & 0.026 & 8 & \\
\hline 401.7 & -0.637 & 0.015 & 5 & -0.784 & 0.018 & 9 & -0.152 \\
\hline 422.6 & -0.479 & 0.051 & 5 & -0.776 & 0.022 & 5 & -0.090 \\
\hline 440.3 & -0.339 & 0.016 & 7 & -0.672 & 0.029 & 12 & -0.057 \\
\hline 462.3 & -0.170 & 0.016 & 4 & -0.436 & 0.014 & 4 & 0.000 \\
\hline 482.3 & -0.039 & 0.054 & 4 & -0.252 & 0.018 & 5 & -0.084 \\
\hline 501.7 & 0.000 & 0.019 & 12 & -0.142 & 0.011 & 16 & -0.121 \\
\hline 522.0 & -0.056 & 0.055 & 5 & -0.041 & 0.012 & 5 & -0.346 \\
\hline 541.4 & -0.204 & 0.038 & 5 & 0.000 & 0.026 & 4 & -0.527 \\
\hline 562.0 & -0.461 & 0.033 & 6 & -0.036 & 0.017 & 10 & -0.808 \\
\hline 582.0 & -0.940 & 0.173 & 4 & -0.239 & 0.019 & 5 & -1.195 \\
\hline 603.0 & -1.520 & 0.043 & 6 & -0.538 & 0.018 & 7 & -1.792 \\
\hline 620.6 & -1.996 & 0.027 & 7 & -0.944 & 0.014 & 9 & -2.358 \\
\hline 641.1 & -2.747 & 0.019 & 4 & -1.473 & 0.009 & 6 & -2.841 \\
\hline 662.0 & -3.396 & 0.033 & 6 & -2.179 & 0.035 & 7 & \\
\hline 681.1 & -4.027 & 0.010 & 6 & -2.880 & 0.036 & 6 & \\
\hline 701.1 & -4.660 & 0.030 & 7 & -3.498 & 0.038 & 9 & \\
\hline 722.0 & -5.258 & 0.050 & 7 & -4.207 & 0.052 & 5 & \\
\hline 740.6 & -5.953 & 0.033 & 5 & -4.692 & & 1 & \\
\hline 760.4 & -6.443 & 0.115 & 3 & & & & \\
\hline
\end{tabular}

The sensitivity values for each wavelength are given as $\log S$, where a sensitivity of $1.0(\log S=0$ ) is given to the wavelength of maximum sensitivity for each cell type ( $502 \mathrm{~nm}$ for rods, $541 \mathrm{~nm}$ for $M$-cones, and $462 \mathrm{~nm}$ for $\mathrm{S}$-cones).

A

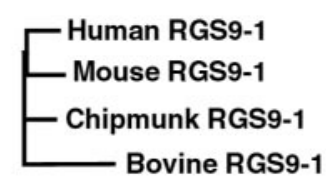

B
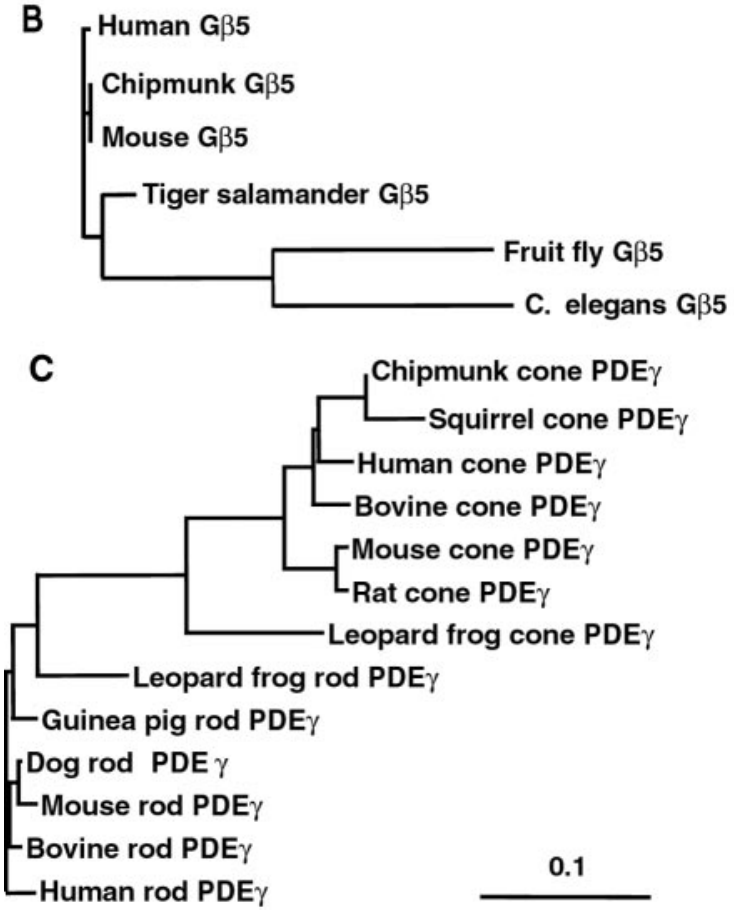

Figure 4. Phylogenetic trees calculated from the amino acid sequences of $\operatorname{RGS}(A), \mathrm{G}_{\beta 5}(B)$, and $\operatorname{PDE} \gamma(C)$ by the neighbor-joining method. The horizontal distances are proportional to the percent differences in amino acid sequences. Scale bar, $10 \%$ replacement of an amino acid per site.

to chipmunk PDE, each mole of recombinant chipmunk cone PDE $\gamma$ inhibited $1781 \pm 109$ mol of cGMP hydrolysis per second, indicating similar potencies in PDE inhibition, as observed previously for bovine cone PDE $\gamma$ (Hamilton et al., 1993).

Rod PDE $\gamma$ can enhance the GAP activity of RGS9-1/G $\mathrm{G}_{\beta 5 \mathrm{~L}}(\mathrm{He}$ et al., 2000; Skiba et al., 2000). To find out whether chipmunk cone PDE $\gamma$ has similar RGS9-1 GAP activity enhancement activity, GTPase single turnover assays were performed in bovine ROS containing $10 \mu \mathrm{M}$ rhodopsin (Fig. 5C). Chipmunk cone and bovine rod recombinant PDE $\gamma$ increased RGS9-1/G $\mathrm{G}_{\beta 5 \mathrm{~L}}$-mediated hydrolysis of GTP by transducin with similar potencies; the same concentrations of recombinant proteins led to similar GTP hydrolysis rates, with a threefold acceleration above basal hydrolysis at a concentration of $50 \mathrm{~nm}$ in each case.

\section{Quantification of proteins}

To quantify the levels of phototransduction proteins that determine the lifetime of effector activation through regulation of the kinetics of G-protein GTP hydrolysis, we determined the molar ratios of RGS9-1 and PDE $\gamma$ to visual pigments in cone-dominant chipmunk and rod-dominant mouse and bovine retinas. The amounts of visual pigments were quantified by difference spectrophotometry. Figure $3 B$ shows the chipmunk retina-RPE extract difference spectrum, with a maximal value at $534 \mathrm{~nm}$. Because in chipmunk retina, there are three kinds of visual pigments, rhodopsin, mid-wavelength-sensitive (M-cone) pigment, and short-wavelength-sensitive (S-cone) pigment, the difference spectrum is a linear combination of the difference spectra of the two cone pigments and rhodopsin. To quantify cone pigments, we generated model spectra (Fig. 3A) on the basis of our spectral sensitivity data (Table 2) as described in Materials and Methods and used a measured spectrum of bovine metarhodopsin II as an approximation of the spectra for all three photoexcited chipmunk pigments (Fig. $3 A$ ). Figure $3 B$ shows a linear combination of the model spectra from Figure $3 A$ fit to the observed difference spectrum in the range of 400-600 $\mathrm{nm}$. The smooth curve is the result predicted for a molar ratio of $\mathrm{M}$ pigment/rhodopsin/S pigment of 1:0.3:0.05, assuming equal extinction coefficients at the absorbance peak for each. The proportion of total visual pigment contributed in this fit by rhodopsin, $22 \%$, is consistent with our immunofluorescence results indicating that rods make up $25 \%$ of total photoreceptors. Our results do not provide an accurate estimate of the relative numbers of $\mathrm{S}$-cones or the amounts of S pigments, although they are clearly much lower than the numbers for $\mathrm{M}$-cones and rods. By using the 

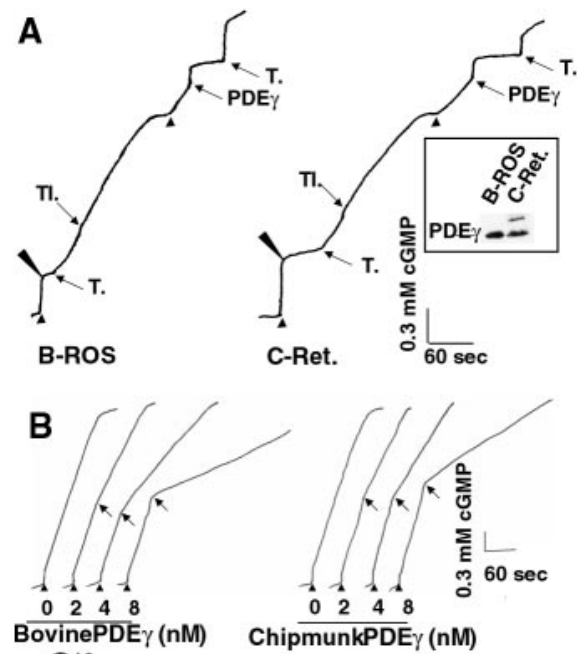

BovinePDE $\gamma(\mathrm{nM})$ ChipmunkPDE $\gamma(\mathrm{nM})$
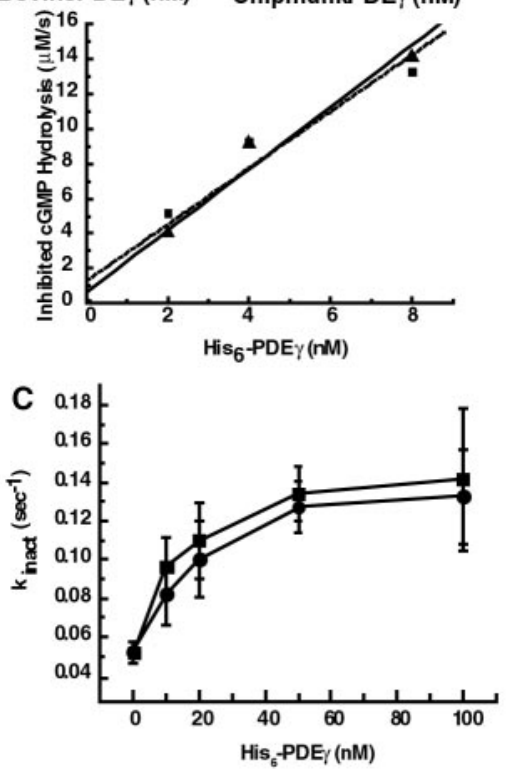

Figure 5. Biochemical properties of chipmunk cone PDE and PDE $\gamma . A$, pH recordings from chipmunk retina homogenate (C-Ret.) and bovine ROS (B-ROS) to test activity of bovine rod PDE and chipmunk cone PDE. Each sample contained 2 nм PDE $\gamma$, as estimated by immunoblots (inset) and densitometry. PDE was activated by removal of inhibitory subunit PDE $\gamma$ using tryp$\sin (T$.$) . The hydrolysis of CGMP by PDE leads to a decrease in \mathrm{pH}$, shown as positive deflection on the $y$-axis. Inhibition of PDE was restored by addition of bovine recombinant PDE $\gamma$. Left, Activity of bovine PDE; right, activity of chipmunk PDE. TI, Soybean trypsin inhibitor. The long arrowheads indicate time 0 , when bovine ROS or chipmunk retina homogenate was added, and short arrowheads indicate the addition of $2 \mathrm{mM} \mathrm{CGMP.} \mathrm{B,} \mathrm{inhibition} \mathrm{of} \mathrm{PDE} \mathrm{activity} \mathrm{followed} \mathrm{by} \mathrm{pH}$ recording. Top, At the indicated times, first trypsin-activated PDE and then indicated amounts of $\mathrm{His}_{6}$-tagged PDE $\gamma$ (chipmunk cone or bovine rod) were added to a reaction vessel containing 2 mu cGMP. Hydrolytic velocity ( $d[\mathrm{cGMP}] / d t$ ) is proportional to the slope at each point along the traces. Bottom, Inhibitory activities of bovine rod (triangles) and chipmunk cone PDE $\gamma$ (squares) are plotted along with linear least squares fits of decreases in CGMP hydrolytic velocity ( $y$-axis) as a function of added PDE $\gamma$. The inhibitory activities calculated from the slopes are $1773 \pm 207$ mol of CGMP hydrolysis per second inhibited per mole of bovine rod PDE $\gamma$ and $1620 \pm 275 \mathrm{~mol}$ of cGMP hydrolysis per second inhibited per mole of chipmunk cone PDE $\gamma$. C, stimulation of GAP activity. The first-order rate constants for GTP hydrolysis in bovine rod outer segment membranes measured under single-turnover conditions are plotted as a function of concentrations of added recombinant PDE $\gamma$ from bovine rods (squares) or chipmunk cones (circles).

reasonable assumption that the cone visual pigments' extinction coefficients are similar to those of other visual pigments $\left(\sim 40,000 \mathrm{M}^{-1} \cdot \mathrm{cm}^{-1}\right.$; Vissers et al., 1998$)$, a total cone pigment concentration of $0.60 \mu \mathrm{M}$ was determined for the sample shown.
A

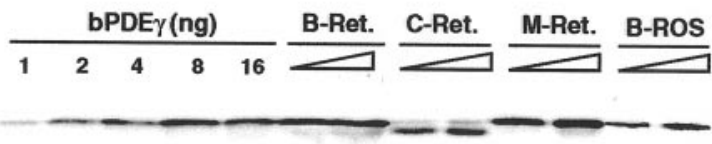

B

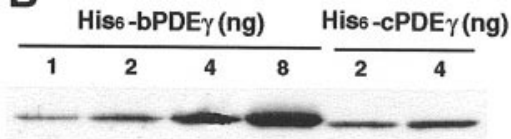

C
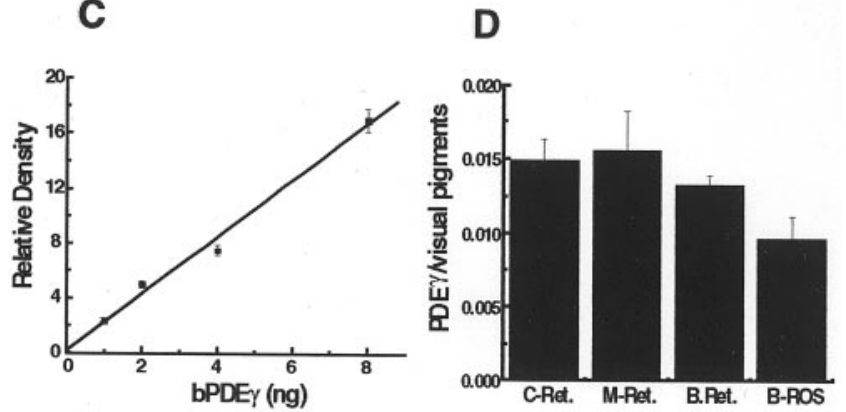

Figure 6. Determination of PDE $\gamma$ levels by quantitative immunoblots. $A$, Examples of immunoblots used to create standard curves from PDE $\gamma$ purified from bovine retina and to determine amounts in each sample. $B$-Ret., Bovine retinal extract; $M$-Ret., murine retinal extract; C-Ret., chipmunk retinal extract; $B$-ROS, bovine rod outer segment homogenate. $B$, Example of immunoblots used to calibrate relative sensitivity of anti-PDE $\gamma$ for chipmunk cone PDE $\gamma$ using purified his 6 -tagged recombinant proteins. C, Example of a standard curve for purified bovine PDE $\gamma$ from the blot in A.D, Ratios of PDE $\gamma$ to rhodopsin or cone pigment in chipmunk (C-ret.), mouse (M-ret.), and bovine ( $B$-ret.) retinas and in bovine rod outer segments $(B-R O S)$. The ratios are $0.0132 \pm 0.007$ in bovine retina, $0.0143 \pm 0.0015$ in chipmunk retina, $0.0155 \pm 0.0028$ in mouse retina, and $0.0096 \pm 0.0016$ in bovine ROS.

The amounts of rhodopsin in rod-dominant bovine and mouse retina and bovine ROS samples were quantified by difference spectrophotometry as well.

To determine the amounts of RGS9-1 and PDE $\gamma$ from different samples, Western blots, followed by densitometry, were performed, and the results were compared with standard curves generated with purified proteins as described in Materials and Methods.

Similar molar ratios of PDE $\gamma$ to visual pigments were obtained in chipmunk, 1:68, mouse, 1:65, and bovine retinas, 1:76 (Fig. 6D), indicating similar relative concentrations of PDE in cones and rods. Bovine rod outer segments, purified from frozen retinas, had a slightly lower ratio of PDE $\gamma$ to rhodopsin, 1:104, likely because of loss of the soluble form of PDE associated with the PDE $\delta$ subunit (Gillespie et al., 1989; Florio et al., 1996). The molar ratio of RGS9-1 to cone pigments in chipmunk retina was determined (Fig. 7E) to be $\sim 1: 62,>14$-fold higher than that in purified bovine ROS, 1:910, and $\sim 10$ times higher than the ratio in bovine and mouse retina, 1:610. Because the molar ratios of visual pigments to transducin are not very different between rods and cones (Tachibanaki et al., 2001), these results indicate that there is a 10-fold higher ratio of RGS9-1 to transducin in cones than in rods. The total concentrations of RGS9-1 and PDE $\gamma$, which work together to achieve maximal transducin GTPase acceleration, are very similar in cones, whereas in rods there is an almost 10-fold excess of PDE $\gamma$ over RGS9-1. The higher concentration of RGS9-1 in cones may be important in the faster recovery of light responses in cones. 


\section{C}

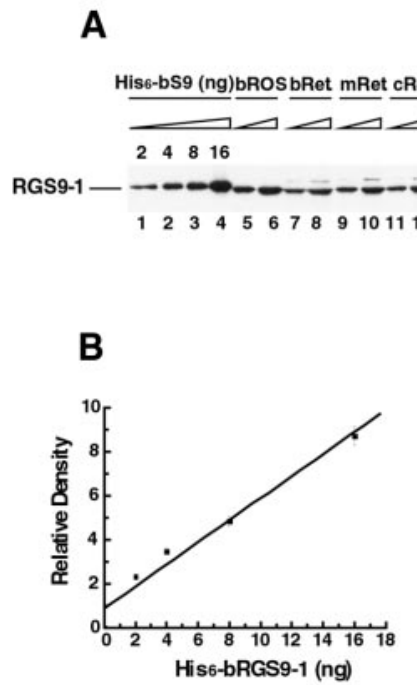

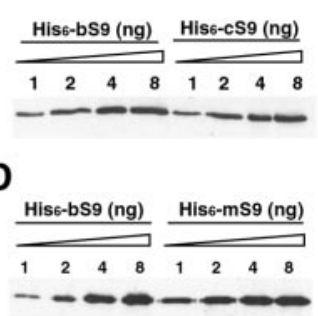

E

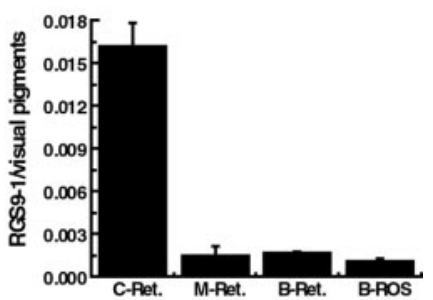

Figure 7. Determination of RGS9-1 levels by quantitative immunoblots. $A$, Examples of immunoblots used to generate standard curves and to determine amounts in each sample. $B$, Example of a standard curve for his 6 -RGS9-1 (bovine). C, D, Examples of immunoblots used to calibrate relative sensitivity of RGS9-1-specific antibodies for RGS9-1 from bovine (His ${ }_{6}-b S 9$ ), chipmunk (His ${ }_{6}-\mathrm{CS} 9$ ), and mouse (His $-\mathrm{mS} 9$ ). E, Ratios of RGS9-1 to rhodopsin or cone pigment in chipmunk retina (C-Ret.), $0.0157 \pm 0.0016$; mouse retina (M-Ret.), $0.0015 \pm 0.0006$; and bovine retina (B-Ret.), $0.0016 \pm 0.0001$; and in bovine rod outer segments ( $B-R O S), 0.0011 \pm$ 0.0004 .

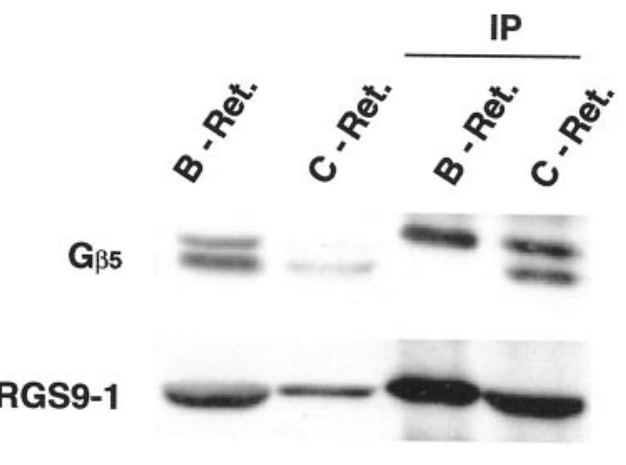

Figure 8. Coimmunoprecipitation of both long and short isoforms of $\mathrm{G}_{\beta 5}$ with RGS9-1 in chipmunk retina. RGS9-1 and associated proteins were immunoprecipitated with immobilized RGS9-1-specific antibodies as described in Materials and Methods. The immunoprecipitates were analyzed by SDS-PAGE and immunoblotting using antibodies specific for RGS9 (bottom panel) or $\mathrm{G}_{\beta 5}$ (top panel; antibody recognizes a peptide epitope present in both isoforms). The left two lanes in each panel are total retinal homogenates from $50 \mu \mathrm{g}$ of bovine retina (B-Ret.) or $10 \mu \mathrm{g}$ of chipmunk retina (C-Ret.), and the right two lanes are the immunoprecipitates (IP; from 100 and $20 \mu \mathrm{g}$, respectively).

\section{Both $\mathrm{G}_{\beta 5 \mathrm{~L}}$ and $\mathrm{G}_{\beta 5 \mathrm{~S}}$ bind to RGS9-1 in chipmunk cones}

RGS9-1 forms a complex with $\mathrm{G}_{\beta 5 \mathrm{~L}}$ in photoreceptor outer segments of rod-dominant mouse and bovine retinas, and the proteins are mutually dependent on one another for expression and stability (Makino et al., 1999; Chen et al., 2000; He et al., 2000). From previous studies, the molar ratio of RGS9-1 to $\mathrm{G}_{\beta 5 \mathrm{~L}}$ appears to be very close to $1: 1$ in rod photoreceptors. To find out whether the molar ratio of RGS9-1 to $\mathrm{G}_{\beta 5 \mathrm{~L}}$ is similar in cone outer segments, we performed immunoblots of chipmunk retina using $G_{\beta 5}$ antibodies. Surprisingly, a much smaller ratio of $\mathrm{G}_{\beta 5 \mathrm{~L}}$ to RGS9-1 immunoblot signal was found in chipmunk retina homogenate compared with that in bovine retina homogenate (Fig. 8) on the same blot. The difference in immunoblot $\mathrm{G}_{\beta 5 \mathrm{~L}}$ signal is unlikely to be attributable to

differences in antibody sensitivity, because the epitope recognized by our antipeptide antibodies is identical in bovine and chipmunk $\mathrm{G}_{\beta 5 \mathrm{~L}}$. To find out whether some RGS9-1 is associated with the short form, $\mathrm{G}_{\beta 5 \mathrm{~S}}$, in chipmunk cones, RGS9-1 GAP complexes were immunoprecipitated from chipmunk retina homogenate using anti-RGS9-1c antibody. In the precipitated pellets, $G_{\beta 5 L}$ and $G_{\beta 5 S}$ were found in similar amounts (Fig. 8). Because the measurements described above indicate that $>96 \%$ of the RGS9-1 in chipmunk retina is in cones, this result indicates that, in contrast to the exclusive association of RGS9- 1 with $\mathrm{G}_{\beta 5 \mathrm{~L}}$ in bovine and murine rods, RGS9-1 associates with similar amounts of $G_{\beta 5 L}$ and $G_{\beta 5 s}$ in chipmunk cones.

\section{Discussion}

The differences observed in rod and cone photoresponses in the chipmunk, like differences between rods and cones of other species, likely arise at several steps in the phototransduction cascade. Candidates for key biochemical differences giving rise to lower sensitivity and faster recovery are the photopigments themselves, lifetimes of activated pigments, activation of the G-proteins by light-activated pigments, lifetimes of activated G-proteins, Gprotein-effector coupling, cGMP-gated channel properties, and differences in $\mathrm{Ca}^{2+}$ concentrations and $\mathrm{Ca}^{2+}$-regulatory mechanisms feeding back on the other steps and on guanylate cyclase activity. There have been only a few biochemical studies of isolated cone pigments, but these suggest that the complex with 11-cis-retinal may be less stable than that formed by rhodopsin both with respect to thermal isomerization (Birge and Barlow, 1995), leading to greater dark noise, and with respect to dissociation of retinal, which could lead both to increased background attributable to weak activation by apo-opsins on dissociation of 11-cis-retinal in the dark and to rapid inactivation attributable to rapid dissociation of all-trans retinal after photoactivation. A recent study of isolated carp cones (Tachibanaki et al., 2001) reported that the gain of phototransduction reactions was much lower than in rod outer segments; however, direct measurements of G-protein activation by human and chicken greensensitive cone pigments (Imai et al., 1997; Vissers et al., 1998) and Xenopus short-wavelength visual pigments (Starace and Knox, 1997; Babu et al., 2001) suggest that the efficiency of rod transducin activation by cone pigment equivalents of metarhodopsin II is only approximately twofold lower than activation by rod metarhodopsin II. Thermal decay of the metarhodopsin-like species has been consistently reported to be much faster for cone pigments than for rhodopsin, and the study of carp cones also revealed much faster phosphorylation and phosphorylation-induced inactivation. Thus the catalytic efficiency of photoexcited cone pigments is less likely to account for the differences in sensitivity than is the dramatically reduced lifetime of this catalytically active state. Rapid truncation of the rise in activated transducin is consistent with our observation of more rapid times to peak in chipmunk cone responses than in rod responses and with the 10-fold lower effective amplification.

Rapid inactivation of photoexcited pigment by itself is not sufficient to account for the rapid recovery kinetics observed in cones of chipmunks and other species. Recovery requires both restoration of cGMP levels through guanylate cyclase activation by light-induced reduction in intracellular $\left[\mathrm{Ca}^{2+}\right]$ and recovery of phosphodiesterase activity to its dark state. Results from RGS9 knock-out mice (Chen et al., 2000; Lyubarsky et al., 2001) have revealed that prompt deactivation of phosphodiesterase depends in both rods and cones on RGS9-1-mediated acceleration of G-protein GTP hydrolysis. It is striking that although the identical GAP protein is present in rods and cones, their concentrations differ by more than an order of magnitude. Although genetic 
deletion of RGS9-1 did not measurably affect the rising phases or amplitudes of rod responses (Chen et al., 2000), because acceleration of transducin GTP hydrolysis is likely to occur much more rapidly in cones as a result of high RGS9-1 concentrations, GTP hydrolysis may contribute in cones to lowering gain in the rising phases of the responses as well. The instantaneous rate of production of activated G-protein in this phase is the difference between the rate of activation by light-activated pigment and the rate of inactivation by GTP hydrolysis. Thus rapid GTP hydrolysis in cones may contribute somewhat to lowered sensitivity as well as to faster recovery. If so, slowing of GTP hydrolysis by inactivation of RGS9-1 would be expected to increase sensitivity. Electroretinogram recordings of cone responses in mice lacking a functional RGS9 gene do indeed show a more than twofold increase in sensitivity compared with wild-type mice (Lyubarsky et al., 2001). The sensitivity increase was detected in the cone b-wave, which is driven by cone responses but does not derive directly from them. Because the cone a-wave, which has a more direct contribution from the cones themselves, is a rather weak and noisy signal in mice, a sensitivity difference on the order of twofold cannot be reliably detected. The observation of a twofold difference in b-wave sensitivity and failure to detect a larger sensitivity increase in the a-wave both suggest that higher RGS9-1 concentrations in cones are not sufficient to explain the much lower gain and sensitivity of cones compared with rods that we have observed. It seems likely that RGS9-1 plays a major role in recovery kinetics and a lesser role in sensitivity.

An unexpected difference we observed between cones and rods is the presence of approximately equal proportions of each isoform of the GAP subunit $\mathrm{G}_{\beta 5}$, bound to RGS9-1 in chipmunk cones, in contrast to the apparently exclusive association of the long isoform $\mathrm{G}_{35 \mathrm{~L}}$ with RGS9-1 in rods (Makino et al., 1999; Chen et al., 2000). Mice lacking the RGS9 gene also lack the long variant $\mathrm{G}_{\beta 5 \mathrm{~L}}$ but not the short variant $\mathrm{G}_{\beta 5 \mathrm{~S}}$ (Chen et al., 2000), so it seems likely that the short variant is responsible for the synaptic staining observed; the antibodies used do not distinguish between the variants. $G_{35 S}$ can associate with RGS11, RGS6, or RGS7 (Posner et al., 1999; Kovoor et al., 2000; Witherow et al., 2000; Zhang and Simonds, 2000) and has been reported previously to be bound to RGS7 in retinal extracts (Cabrera et al., 1998). It is likely that one or more of these other RGS proteins is bound to $\mathrm{G}_{\beta 5}$ in the outer plexiform layer. Two recent comparisons of recombinant proteins (He et al., 2000; Skiba et al., 2001) found little difference between the values of the physiologically relevant parameter for catalytic efficiency, $k_{\mathrm{cat}} / K_{\mathrm{m}}$, for full-length RGS9-1 complexed with $\mathrm{G}_{\beta 5 \mathrm{~L}}$ compared with the complex with the short isoform $G_{\beta 55}$. It remains to be determined why rod outer segments contain only one of the $G_{\beta 5}$ splice variants, whereas cone outer segments contain both.

In contrast to the striking differences in RGS9-1 levels, the enzymatic properties and concentrations of PDE appear to be very similar in rods and cones. Many of the differences in PDE sequences between rods and cones are conserved across a number of species, but few striking differences between the properties of rod and cone PDE variants have been detected. PDE $\gamma$ has two different activities important for phototransduction, inhibition of PDE catalytic subunits and enhancement of RGS9-1 GTPase acceleration. These activities are also similar in the rod and cone variants. Although we were not able to assess the efficiency with which transducin activates PDE in cones in our crude retina preparations, bovine cone PDE has been reported previously to be activated by transducin more efficiently than rod PDE (Gillespie and Beavo, 1988).
Although our measurements suggest that GTP hydrolysis plays an important role in determining the differences in cone and rod photoresponses, whereas catalytic properties of PDE likely do not, there are clearly other biochemical differences underlying the differences in photoresponses. There is evidence suggesting that differences in regulation of and by $\mathrm{Ca}^{2+}$ plays an especially important role in the differences between rods and cones. The fraction of photocurrent carried by $\mathrm{Ca}^{2+}$ in cones $(\sim 35 \%)$ is substantially greater than that in rods ( $\sim 20 \%$; Ohyama et al., 2000,2002$)$, whereas $\mathrm{Ca}^{2+}$ extrusion is faster in cones (Korenbrot, 1995; Sampath et al., 1999), so that flashes eliciting similar current changes will give rise to larger changes in $\left[\mathrm{Ca}^{2+}\right]$ in cones than in rods. Moreover, the [cGMP] dependence of channel gating is sensitive to $\left[\mathrm{Ca}^{2+}\right]$ over the physiological range in cones (Rebrik et al., 2000). However, the faster response kinetics of cones do not depend entirely on differences in $\mathrm{Ca}^{2+}$ homeostasis, because they are faster even when lightinduced $\mathrm{Ca}^{2+}$ changes are prevented (Nakatani and Yau, 1989; Matthews et al., 1990).

A complete molecular explanation of the differences in rod and cone photoresponses will require further quantification of other key components of the transduction cascade, particularly those involved in $\mathrm{Ca}^{2+}$ feedback and pigment phosphorylation. From the results presented here, it seems clear that chipmunk and other conedominant animals present excellent substrates for such studies.

\section{References}

Angleson JK, Wensel TG (1994) Enhancement of rod outer segment GTPase accelerating protein activity by the inhibitory subunit of cGMP phosphodiesterase. J Biol Chem 269:16290-16296.

Arshavsky VY, Lamb TD, Pugh Jr EN (2002) G proteins and phototransduction. Annu Rev Physiol 64:153-187.

Babu KR, Dukkipati A, Birge RR, Knox BE (2001) Regulation of phototransduction in short-wavelength cone visual pigments via the retinylidene Schiff base counterion. Biochemistry 40:13760-13766.

Baylor DA, Hodgkin AL (1973) Detection and resolution of visual stimuli by turtle photoreceptors. J Physiol (Lond) 234:163-198.

Baylor DA, Nunn BJ, Schnapf JL (1984) The photocurrent, noise and spectral sensitivity of rods of the monkey Macaca fascicularis. J Physiol (Lond) 357:575-607.

Birch DG (1999) Retinal degeneration in retinitis pigmentosa and neuronal ceroid lipofuscinosis: an overview. Mol Genet Metab 66:356-366.

Birge RR, Barlow RB (1995) On the molecular origins of thermal noise in vertebrate and invertebrate photoreceptors. Biophys Chem 55:115-126.

Bowmaker JK, Dartnall HJ, Mollon JD (1980) Microspectrophotometric demonstration of four classes of photoreceptor in an old world primate, Macaca fascicularis. J Physiol (Lond) 298:131-143.

Cabrera JL, de Freitas F, Satpaev DK, Slepak VZ (1998) Identification of the G $\beta 5$-RGS7 protein complex in the retina. Biochem Biophys Res Commun 249:898-902.

Chen CK, Burns ME, He W, Wensel TG, Baylor DA, Simon MI (2000) Slowed recovery of rod photoresponse in mice lacking the GTPase accelerating protein RGS9-1. Nature 403:557-560.

Cowan CW, Fariss RN, Sokal I, Palczewski K, Wensel TG (1998) High expression levels in cones of RGS9, the predominant GTPase accelerating protein of rods. Proc Natl Acad Sci USA 95:5351-5356.

Dartnall HJA (1972) Chapter 4, photosensitivity. In: Handbook of sensory physiology, Vol VII/1, Photochemistry of vision (Dartnall HJA, ed), pp 122-145. New York: Springer-Verlag.

Davis L, Kuehl M, Battey J (1994) Basic methods in molecular biology, Ed 2. Norwalk, CT: Appleton \& Lange.

Dawis SM (1981) Polynomial expressions of pigment nomograms. Vision Res 21:1427-1430.

Detwiler PB, Ramanathan S, Sengupta A, Shraiman BI (2000) Engineering aspects of enzymatic signal transduction: photoreceptors in the retina. Biophys J 79:2801-2817.

Ditchburn RW (1963) Light, Vol I, pp 94-97. New York: Interscience.

Florio SK, Prusti RK, Beavo JA (1996) Solubilization of membrane-bound rod phosphodiesterase by the rod phosphodiesterase recombinant delta subunit. J Biol Chem 271:24036-24047.

Gill SC, von Hippel PH (1989) Calculation of protein extinction coefficients 
from amino acid sequence data. Anal Biochem [Erratum (1990) 189:283] 182:319-326.

Gillespie PG, Beavo JA (1988) Characterization of a bovine cone photoreceptor phosphodiesterase purified by cyclic GMP-Sepharose chromatography. J Biol Chem 263:8133-8141.

Gillespie PG, Prusti RK, Apel ED, Beavo JA (1989) A soluble form of bovine rod photoreceptor phosphodiesterase has a novel $15-\mathrm{kDa}$ subunit. J Biol Chem 264:12187-12193.

Hamer RD (2000) Analysis of $\mathrm{Ca}^{++}$-dependent gain changes in PDE activation in vertebrate rod phototransduction Mol Vis 6:265-286.

Hamilton SE, Prusti RK, Bentley JK, Beavo JA, Hurley JB (1993) Affinities of bovine photoreceptor cGMP phosphodiesterases for rod and cone inhibitory subunits. FEBS Lett 318:157-161.

Harlow E, Lane D (1988) Antibodies: a laboratory manual. New York: Cold Spring Harbor Laboratories.

Harris DC, Bertolucci MD (1978) Symmetry and spectroscopy, p 336. New York: Oxford UP.

He W, Cowan CW, Wensel TG (1998) RGS9, a GTPase accelerator for phototransduction. Neuron 20:95-102.

He W, Lu L, Zhang X, El-Hodiri HM, Chen CK, Slep KC, Simon MI, Jamrich M, Wensel TG (2000) Modules in the photoreceptor RGS9-1: G $\beta 5 \mathrm{~L}$ GTPase-accelerating protein complex control effector coupling, GTPase acceleration, protein folding, and stability. J Biol Chem 275:37093-37100.

Hicks D, Sahel J (1999) The implications of rod-dependent cone survival for basic and clinical research. Invest Ophthalmol Vis Sci 40:3071-3074.

Hu G, Jang GF, Cowan CW, Wensel TG, Palczewski K (2001) Phosphorylation of RGS9-1 by an endogenous protein kinase in rod outer segments. J Biol Chem 276:22287-22295.

Hurley JB, Stryer L (1982) Purification and characterization of the gamma regulatory subunit of the cyclic GMP phosphodiesterase from retinal rod outer segments. J Biol Chem 257:11094-11099.

Imai H, Kojima D, Oura T, Tachibanaki S, Terakita A, Shichida Y (1997) Single amino acid residue as a functional determinant of rod and cone visual pigments. Proc Natl Acad Sci USA 94:2322-2326.

Korenbrot JI (1995) $\mathrm{Ca}^{2+}$ flux in retinal rod and cone outer segments: differences in $\mathrm{Ca}^{2+}$ selectivity of the cGMP-gated ion channels and $\mathrm{Ca}^{2+}$ clearance rates. Cell Calcium 18:285-300.

Kovoor A, Chen CK, He W, Wensel TG, Simon MI, Lester HA (2000) Coexpression of $\mathrm{G} \beta 5$ enhances the function of two $\mathrm{G} \gamma$ subunit-like domaincontaining regulators of $\mathrm{G}$ protein signaling proteins. J Biol Chem 275:3397-3402.

Kraft TW (1988) Photocurrents of cone photoreceptors of the goldenmantled ground squirrel. J Physiol (Lond) 404:199-213.

Kraft TW, Schneeweis DM, Schnapf JL (1993) Visual transduction in human rod photoreceptors. J Physiol (Lond) 464:747-765.

Kraft TW, Neitz J, Neitz M (1998) Spectra of human L cones. Vision Res 38:3663-3670.

Lamb TD, Pugh ENJ (1992) A quantitative account of the activation steps involved in phototransduction in amphibian photoreceptors. J Physiol (Lond) 449:719-758.

Lamb TD, McNaughton PA, Yau KW (1981) Spatial spread of activation and background desensitization in toad rod outer segments. J Physiol (Lond) 319:463-496.

Leskov IB, Klenchin VA, Handy JW, Whitlock GG, Govardovskii VI, Bownds MD, Lamb TD, Pugh Jr EN, Arshavsky VY (2000) The gain of rod phototransduction: reconciliation of biochemical and electrophysiological measurements. Neuron 27:525-537.

Levenberg K (1944) A method for the solution of certain problems in least squares. Quart Appl Math 2:164-168.

Liebman PA, Evanczuk AT (1982) Real time assay of rod disk membrane cGMP phosphodiesterase and its controller enzymes. Methods Enzymol 81:532-542.

Lyubarsky AL, Naarendorp F, Zhang X, Wensel T, Simon MI, Pugh Jr EN (2001) RGS9-1 is required for normal inactivation of mouse cone phototransduction. Mol Vis 7:71-78.

Makino ER, Handy JW, Li T, Arshavsky VY (1999) The GTPase activating factor for transducin in rod photoreceptors is the complex between RGS9 and type 5 G protein $\beta$ subunit. Proc Natl Acad Sci USA 96:1947-1952.

Malinski JA, Wensel TG (1992) Membrane stimulation of cGMP phosphodiesterase activation by transducin: comparison of phospholipid bilayers to rod outer segment membranes. Biochemistry 31:9502-9512.

Marquardt DW (1963) An algorithm for least-squares estimation of nonlinear parameters. J Soc Ind Appl Math 11:431-441.
Masland RH (2001) The fundamental plan of the retina. Nat Neurosci 4:877-886.

Matthews HR, Fain GL Murphy RLW, Lamb TD (1990) Light adaptation in cone photoreceptors of the salamander: a role for cytoplasmic calcium. J Physiol (Lond) 420:447-469.

Nakatani K, Yau K-W (1989) Sodium-dependent calcium extrusion and sensitivity regulation in retinal cones of the salamander. J Physiol (Lond) 409:525-548.

Nikonov S, Pugh Jr EN (1998) Kinetics of recovery of the dark-adapted salamander rod photoresponse. J Gen Physiol 111:7-37.

Ohyama T, Hackos DH, Frings S, Hagen V, Kaupp UB, Korenbrot JI (2000) Fraction of the dark current carried by $\mathrm{Ca}(2+)$ through cGMP-gated ion channels of intact rod and cone photoreceptors. J Gen Physiol 116:735-754.

Ohyama T, Picones A, Korenbrot JI (2002) Voltage-dependence of ion permeation in cyclic GMP-gated ion channels is optimized for cell function in rod and cone photoreceptors. J Gen Physiol 119:341-354.

Posner BA, Gilman AG, Harris BA (1999) Regulators of G protein signaling 6 and 7. Purification of complexes with $G \beta 5$ and assessment of their effects on $G$ protein-mediated signaling pathways. J Biol Chem 274:31087-31093.

Pugh Jr EN, Lamb TD (1993) Amplification and kinetics of the activation steps in phototransduction. Biochim Biophys Acta 1141:111-149.

Rebrik TI, Kotelnikova EA, Korenbrot JI (2000) Time course and Ca(2+) dependence of sensitivity modulation in cyclic GMP-gated currents of intact cone photoreceptors. J Gen Physiol 116:521-534.

Sagoo MS, Lagnado L (1997) G-protein deactivation is rate-limiting for shut-off of the phototransduction cascade. Nature 389:392-395.

Saitou N, Nei M (1987) The neighbor-joining method: a new method for reconstructing phylogenetic trees. Mol Biol Evol 4:406-425.

Sampath AP, Matthews HR, Cornwall MC, Bandarchi J, Fain GL (1999) Light-dependent changes in outer segment free-Ca2+ concentration in salamander cone photoreceptors. J Gen Physiol 113:267-277.

Schnapf JL, Nunn BJ, Meister M, Baylor DA (1990) Visual transduction in cones of the monkey Macaca fascicularis. J Physiol (Lond) 427:681-713.

Schneeweis DM, Schnapf JL (1999) The photovoltage of macaque cone photoreceptors: adaptation, noise, and kinetics. J Neurosci 19:1203-1216.

Skiba NP, Hopp JA, Arshavsky VY (2000) The effector enzyme regulates the duration of $\mathrm{G}$ protein signaling in vertebrate photoreceptors by increasing the affinity between transducin and RGS protein. J Biol Chem 275:32716-32720.

Skiba NP, Martemyanov KA, Elfenbein A, Hopp JA, Bohm A, Simonds WF, Arshavsky VY (2001) RGS9-G $\beta 5$ substrate selectivity in photoreceptors: opposing effects of constituent domains yield high affinity of RGS interaction with the G protein-effector complex. J Biol Chem 276:37365-37372.

Starace DM, Knox BE (1997) Activation of transducin by a Xenopus short wavelength visual pigment. J Biol Chem 272:1095-1100.

Stryer L, Hurley JB, Fung BK (1983) Transducin and the cyclic GMP phosphodiesterase of retinal rod outer segments. Methods Enzymol 96:617-627.

Tachibanaki S, Tsushima S, Kawamura S (2001) Low amplification and fast visual pigment phosphorylation as mechanisms characterizing cone photoresponses. Proc Natl Acad Sci USA 98:14044-14049.

Thompson JD, Higgins DG, Gibson TJ (1994) CLUSTAL W: improving the sensitivity of progressive multiple sequence alignment through sequence weighting, position-specific gap penalties and weight matrix choice. Nucleic Acids Res 22:4673-4680.

Vissers PM, Bovee-Geurts PH, Portier MD, Klaassen CH, Degrip WJ (1998) Large-scale production and purification of the human green cone pigment: characterization of late photo-intermediates. Biochem J 330:1201-1208.

Wensel TG, Stryer L (1990) Activation mechanism of retinal rod cyclic GMP phosphodiesterase probed by fluorescein-labeled inhibitory subunit. Biochemistry 29:2155-2161.

Witherow DS, Wang Q, Levay K, Cabrera JL, Chen J, Willars GB, Slepak VZ (2000) Complexes of the $G$ protein subunit $G \beta 5$ with the regulators of $G$ protein signaling RGS7 and RGS9: characterization in native tissues and in transfected cells. J Biol Chem 275:24872-24880.

Wu TH, Ting TD, Okajima TI, Pepperberg DR, Ho YK, Ripps H, Naash MI (1998) Opsin localization and rhodopsin photochemistry in a transgenic mouse model of retinitis pigmentosa. Neuroscience 87:709-717.

Zhang JH, Simonds WF (2000) Copurification of brain G-protein $\beta 5$ with RGS6 and RGS7. J Neurosci 20:RC59(1-5).

Zhang K, Howes KA, He W, Bronson JD, Pettenati MJ, Chen C, Palczewski K, Wensel TG, Baehr W (1999) Structure, alternative splicing, and expression of the human RGS9 gene. Gene 240:23-34. 